\title{
Consumption Volatility and the Cross-Section of Stock Returns*
}

\author{
Roméo Tédongap \\ Université de Montréal, CIRANO and CIREQ
}

First Version: November 2006, This Version: February 2007, Compiled: April 30, 2007

\begin{abstract}
Interesting asset pricing properties of consumption volatility have been put forward in earlier studies, but they were mainly related to the time series dimension of asset returns. A major contribution of this paper will be to characterize and measure its impact in the cross-sectional dimension. We establish empirical facts showing the existence of a strong relationship between macroeconomic uncertainty and stock returns. These facts suggest that consumption volatility risks are highly correlated to short and long horizon risk premia. Moreover, these risks can account for the differences in risk premia across size and book-to-market sorted portfolios, as well as other valuation ratio sorted portfolios. We find that long-run consumption volatility risk is economically important even in the presence of long-run consumption level risk, and that value stocks pay high average returns because they covary more negatively with long-horizon variation in consumption volatility than other stocks. We argue that long-run volatility risk is relevant for interpreting differences in risk compensation across assets. We finally propose a reduced-form general equilibrium model that rationalizes the empirical evidence.
\end{abstract}

Keywords: consumption volatility, volatility risk, cross-section of returns, general equilibrium

JEL Classification: G0, G1, G12, G11

*I thank René Garcia, Nour Meddahi, Bruno Feunou and Jean-Sébastien Fontaine for helpful comments. All errors are mine. Financial support from the Department of Economics of Université de Montréal, the Centre of Interuniversity Research in Quantitative Economics (CIREQ) and the Montreal Institute of Mathematical Finance (IFM2) is gratefully acknowledged. Address for correspondence: Département de Sciences Économiques, Université de Montréal, C.P. 6128, Succ. Centre-Ville, Montréal, Québec, H3C 3J7, Canada. Email: rr.tedongap.nguefack@umontreal.ca. 


\section{Introduction}

The question what do or should investors care about? remains central in Asset Pricing and a variety of models continue to provide alternative answers. Investment opportunities are risky and investors face multiple sources of financial and macroeconomic risks that they should hedge themselves against when constructing their portfolios. This paper provides and supports the evidence that long-term investors care not only about variation between future and present consumption levels, but also and perhaps mostly about variation between future and present macroeconomic uncertainties. As in Bansal and Yaron (2004), macroeconomic uncertainty here refers to the volatility of aggregate consumption. We answer the following question: Are differences in risk premia across stocks due to the heterogeneity in their exposure to consumption volatility risk? We find that portfolios with high risk premia have high negative covariances with long-horizon variation in consumption volatility. This is true for short-period investments, as well as for long-period investments. Therefore, it suggests that investors dislike assets paying less for higher future macroeconomic uncertainty relative to the present. Consequently, they will demand a higher risk premium for holding such assets.

The critical consideration that consumption volatility varies over time is central in this study. A recent literature emphasizes that the relationship between macroeconomic uncertainty and investment opportunities is crucial to understand the behavior of asset prices (see for example Bansal and Yaron (2004)). Kandel and Stambaugh (1990) find that consumption volatility is predicted by three financial variables and moreover, it varies in relation with the business cycle. ${ }^{1}$ That is, consumption volatility tends to be larger at the end of recessions or immediately after them. Markov-Switching models estimated on consumption data support that consumption growth volatility varies across different regimes (Kandel and Stambaugh (1991), Bonomo and Garcia (1993), Lettau, Ludvigson and Wachter (2006)). Modelling consumption volatility as a GARCH process, Bansal, Khatchatrian and Yaron (2004) find a significant ARCH effect. They also show that this measure of consumption volatility is predicted by the price-dividend ratio.

As choosing a portfolio is equivalent to buying various types of risks, asset pricing models aim at identifying relevant financial and macroeconomic risks that are priced, and at determin-

\footnotetext{
${ }^{1}$ They regress consumption volatility at the quarter $t$ on (a) the difference at the end of quarter $t-1$ between Moody's average yield on bonds rated Baa and bonds rated Aaa, (b) the difference at the end of quarter $t-1$ between the Aaa yield and the yield on a U.S. Treasury bill with maturity closest to one month, and (c) the dividend-price ratio at the quarter $t-1$ for the value-weighted portfolio of NYSE stocks. The chi-squared statistic does not reject the hypothesis that consumption volatility does not depend on the predictive variables.
} 
ing if these risks justify the observed pattern across historical asset returns. In other words, they investigate if a relationship between a group of asset returns and the corresponding asset risks is monotonic, has the right sign and is economically significant. Roughly speaking, these models try to explain the size and the value premia. The size premium comes from the fact that stocks of firms with small capitalization (small stocks) have historically paid higher average returns than those of firms with large capitalization (large stocks). On the other hand, stocks of firms with a high ratio of book value to market value (value stocks) have historically paid higher average returns than those of firms with a low ratio of book value to market value (growth stocks): the difference is known as the value premium.

Since a cross-sectional model with the level of consumption itself has a weak performance in justifying differences across stock returns, a part of the literature continues to deal with consumption by motivating higher moments of consumption as possible priced factors. The volatility of consumption can provide additional information about consumption that should be taken into account in consumption-based cross-sectional models. However, while some useful asset pricing implications of models involving time-varying consumption volatility were put forward in earlier studies (Bansal and Yaron (2004), Tauchen (2005), Eraker (2006)), to the best of our knowledge, the implications of this measure of macroeconomic uncertainty have not been investigated for the cross-section of stock returns, and then constitute the focus of this study.

Empirical studies of asset pricing models typically examine the cross-sectional implications of macroeconomic factors for short-period investments by focusing only on one-period returns. However, Bansal, Dittmar and Kiku (2005) show that the risk-return relationship varies extensively as the investment horizon increases.

We consider multihorizon investments where the investor stays in stocks for the first periods, then switches to the safe asset and stays on it until the end of the investment period. We then study how returns on such investments react to the variation in consumption level as well as the variation in consumption volatility between the end and the beginning of the investment period. We use a parametric measure of consumption volatility inferred from a GARCH specification. We examine cross-sectional implications of each of these macroeconomic factors for short and long-period holding returns. We use the standard measure of the asset risk, the covariance between asset payoff and risk factor.

Plotting volatility risks against horizon across one-period portfolios sorted on book-tomarket, dividend-to-price, earnings-to-price and cash flows-to-price ratios, we find that there is a significant difference between portfolio risks as the investment horizon increases. Moreover, 
these risks exhibit a pattern that generally matches that of risk premia across these dimensions. This means that growth stocks have a lower volatility risk than value stocks and the volatility risk of the market portfolio lies between these extreme risks.

We also examine the cross-sectional implications of volatility risks for returns on portfolios hold more than one period. The pattern of volatility risks across long-period portfolios sorted on book-to-market, dividend-to-price, earnings-to-price and cash flows-to-price dimensions, confirms that value is riskier than growth. Moreover, for most of the investment horizons, volatility risks are more correlated with long-period returns on the Fama and French size and book-to-market sorted portfolios than consumption risk.

As we show that portfolios with high risk premia covary more negatively with variations in consumption volatility, we further ask whether this explains their higher average returns. We estimate linear models which link risk premia to covariances of returns with factors and find that the price of long-horizon volatility risk is negative and significantly estimated in the cross-section of long-period returns.

The two macroeconomic factors that we consider in this paper are theoretically motivated by a consumption-based model with a representative investor who values its payoffs through a stochastic discount factor that depends log-linearly on both variations in consumption level and variations in consumption volatility. We further show that it is the case in an affine general equilibrium model like in Tauchen (2005). While the logarithm of the standard SDF of the power utility only depends on the level of consumption, that of the recursive utility depends additionally on consumption volatility through consumption valuation ratios. We model individual asset dividends such that their exposures to a weighted sum of past consumption levels distinguish value from growth stocks. Coupled with Epstein and Zin (1989)'s preference, these dynamics justify the observed pattern of volatility risk across portfolios sorted from growth to value.

This paper belongs to the recent literature that examines whether stock returns can be priced by their exposure to long-run risks. Long-run risks appear to be a key concern in asset markets (Bansal and Yaron (2004), Bansal, Dittmar and Kiku (2005)). Parker and Julliard (2005) consider long-run consumption risk, showing that ultimate consumption risk of assets, measured by the covariance between returns and the long-horizon consumption growth, can account for the value premium. In addition, we consider long-run volatility risk, measured by the covariance of returns with the long-horizon volatility variation. We show that this risk is priced in financial markets and can also account for the value premium. 
This paper also relates to the growing literature that includes volatility factors in crosssectional asset pricing models. As well as the volatility of aggregate consumption, the volatility of the aggregate stock market return provides a measure of macroeconomic uncertainty through the link between financial markets and the real economy, but is not directly related to macroeconomic fundamentals, here the consumption flow. Ang, Hodrick, Xing and Zhang (2006) show that a nonparametric proxy of market volatility is a cross-sectional stock pricing factor $^{2}$. In a parametric approach, Adrian and Rosenberg (2006) model the market return as a GARCH process and decompose its volatility into a short and a long-run component. They find that these volatility components have negative and significant prices of risk in the crosssection of stock returns. Their work can be viewed as using additional information provided by state variables in the market return process to improve the CAPM, while we use additional information provided by state variables in the consumption growth process to improve a cross-sectional consumption-based asset pricing model.

This paper finally builds on work that examines the implications of higher moments of consumption for the cross-section of asset returns. Using household consumption data, Jacobs and Wang (2004) find that the variance of the cross-sectional distribution of consumption growth has some potential to explain asset risk premia. Their result points out that assets with high negative covariance with consumption dispersion also have high returns. We depart from the work of Jacobs and Wang (2004) in that we examine the risk of the volatility of aggregate consumption whereas they focus on the risk of the dispersion in idiosyncratic consumption. Second, as they use microdata to construct risk factors, we use macrodata in this paper. Third, factors differ in what they refer to. While the variance of the cross-sectional distribution of consumption growth is mostly a degree of heterogeneity across individuals, consumption volatility is mostly the degree of the imprecision that affects agents's expectations about future consumption. Fourth as we mention earlier, our factors incorporate long-run risks in consumption volatility. Finally, their work relates to the literature on market incompleteness, whereas our setup rests upon the complete markets assumption that underlies our representative agent framework.

The rest of the paper is organized as follows. Section 2 motivates and discusses the crosssectional risk-return relationship involving different investment horizons and stock holding periods. Section 3 presents the data, establishes relevant empirical facts and discusses empirical risk-return relationships through cross-sectional correlations between mean excess returns and volatility risks. Section 4 estimates risk prices and provides additional empirical findings and

\footnotetext{
${ }^{2}$ To proxy innovations in aggregate market volatility, they use changes in the VIX index from the Chicago Board Options Exchange (CBOE).
} 
diagnostics. Section 5 rationalizes the results from the perspective of existing asset pricing equilibrium models. Section 6 concludes.

\section{Consumption Volatility Risk and the Cross-Section of Asset Returns}

The standard consumption-based asset pricing theory states that an investor cares only about the level of its consumption at each period in time and should then invest in stocks in consequence. However, empirical tests show that the comouvement between one-period asset payoffs and one-period consumption growth fails to explain differences in one-period average returns across assets. The literature has grown so far to address the issue of improving the ability of consumption-based models in understanding risk compensations from asset exposures to good and bad news about consumption. These news can be related either to the consumption level or to time-varying consumption moments.

To explain the aggregate stock market behavior and asset pricing puzzles, Bansal and Yaron (2004) provide a version of the reduced form general equilibrium model in which investors have concerns about risks from the level of consumption growth, from changes in consumption growth forecasts and from changes in consumption volatility. This induces a time-varying equity risk premium which is associated with conditional covariances of return with innovations in these state variables. In their model, if the representative agent prefers early resolution of uncertainty, has both the coefficient of risk aversion and the elasticity of intertemporal substitution greater than one, then volatility carries a positive risk premium. This adds to the growing set of asset pricing properties of consumption volatility which have so far been mainly established in the time series dimension of asset returns.

However, while the reduced form general equilibrium model of Bansal and Yaron (2004) also suggests that consumption volatility could be a cross-sectional pricing factor, the question of how it affects the cross-section of expected returns have received less attention. Stocks with different sensitivities to the volatility of aggregate consumption should have different expected returns as changes in macroeconomic uncertainty induce changes if investment opportunities. Investors' expectations about future consumption are imprecise, and the degree of that imprecision is measured by consumption volatility. Since consumption is the claim on total investor wealth, the imprecision about expected future consumption also reflects the uncertainty about future wealth. In that sense, movements in consumption volatility provide additional news about consumption that are likely to influence investment decisions. For this 
reason, consumption volatility is suspected as empirically relevant for explaining asset returns.

An investor chooses intertemporally its portfolios to face as better as he can bad states of the economy. As well as such an investor dislikes low consumption levels, he also dislikes high uncertainty on future consumption levels. We examine these two concerns of investors by analyzing empirical risk-return relationships involving asset returns and both consumption level and consumption volatility risks.

The failures of the standard consumption-based asset pricing theory in empirical tests brought to researchers to examine relationship between multiperiod returns rather than oneperiod returns, or long-horizon changes in macroeconomic variables rather than one-horizon changes. Parker and Julliard (2005) show that differences in exposure of one-period stock returns to long-horizon consumption growth account for cross-sectional differences in stock risk premia. They argue that slow adjustment of consumption to return data is a reason of why contemporaneous consumption risk fails to explain expected one-period stock returns. While empirical studies typically deal with one-period returns, Bansal, Dittmar and Kiku (2005) study the relation between consumption risk and stock return when the stock holding period is the same as the investment horizon. They show that this risk-return relationship varies extensively by investment horizon, and that consumption risk almost converges to the long-run relation between dividend and consumption as the horizon increases. We also vary the investment horizon and work directly on returns. In addition to the relation with risk from consumption level, we examine the relation with risk from consumption volatility in more general cases where stock holding period is less or equal to the investment horizon.

We consider $N$ stocks denoted $i=1, . ., N$ and and the safe asset $f$. The one-period return of investing the asset $i$ from $t+j-1$ to $t+j$ is denoted $R_{i, t+j}, j \geq 1$. The total investment horizon is denoted $S$. An $S$-period investment in this study starts with a oneperiod investment in the first period and payoffs are reinvested at the beginning of each of the $(S-1)$ subsequent periods. We are interested in risk-return relationships involving returns on long-horizon investments which consist in investing in the same stock for the first periods and then reinvesting payoffs in the safe asset for the remaining periods. Given an investment horizon $S$, the gross return on such an investment can be written:

$$
R_{i t, k, S}=\underbrace{\prod_{j=1}^{k} R_{i, t+j}}_{R_{i t, k}} \prod_{j=k+1}^{S} R_{f, t+j}
$$

and defines the $S$-period gross return formed by investing from time $t$ in the asset $i$ for the first $k$ periods, and then reinvesting its payoffs from date $t+k$ in the safe asset, for the remaining 
$(S-k)$ periods.

The excess return with respect to the return on the investment which consists in staying in the safe asset for the whole period is defined by $R_{i t, k, S}^{e}=R_{i t, k, S}-R_{f t, S}$. Note that $R_{f t, S}$ is not the return on a bond that bought at time $t$ will deliver a unit consumption at time $t+S$. An investor who buys at time $t$ an $S$-horizon investment plan consisting to stay in the safe asset for the whole period is now making a risky decision if $S>1$, since future one-period risk-free rates $R_{f, t+j}, j>1$ are not known at time $t$ and are affected by macroeconomic factors during the investment period. $R_{f t, S}$ is unknown at time $t$ and is not the $S$-period risk-free rate from $t$ to $t+S$.

The risk premium that an investor will require to stay the first $k$ periods in the stock $i$ and the remaining $(S-k)$ periods in the safe asset, instead of staying in the safe asset for the whole period, is defined by the expectation of the corresponding excess return $E\left[R_{i t, k, S}^{e}\right]$. For a given $S$, as the risk-free rate part is common for all returns $R_{i t, k, S}, i=1, . ., N$, the cross-section of average $k$-period stock holding returns can be defined by the vector:

$$
E\left[R_{\cdot t, k, S}^{e}\right]=\left(E\left[R_{1 t, k, S}^{e}\right] \cdot \cdot \cdot E\left[R_{N t, k, S}^{e}\right]\right)^{\top} .
$$

We want to examine the relationship between these returns and two main horizon-dependent macroeconomic factors. Because what guides investors seems to be the comovement between asset payoffs and risk factors, it is appealing to measure the risk for holding an asset as the covariance between the payoff and the risk factor. The sign of this covariance indicates if the asset and the factor move in the same or opposite direction, whereas its magnitude quantifies the degree of this comovement. The first factor denoted:

$$
\Delta c_{t, S}=c_{t+S}-c_{t}=\sum_{j=1}^{S} \Delta c_{t+j}
$$

is the variation in the level of consumption between the end and the beginning of the investment period and also equals the future $S$-horizon consumption growth. The covariance of this factor with an asset return measures the $S$-level risk, or the ultimate consumption risk of the asset if $k=1$, as termed in Parker and Julliard (2005). These authors argue that ultimate consumption risk is a better asset risk measure than the standard consumption risk in the CCAPM, for example if consumption reacts with lags to stock returns. Alternatively, the link between returns and future long-horizon consumption growth can be simply due to the fact that investors are concerned with long-run risks in consumption. For a given $S$, the cross-section of $S$-level risks for $k$-period holding stocks is defined by the vector:

$$
\operatorname{Cov}\left(\Delta c_{t, S}, R_{\cdot t, k, S}^{e}\right)=\left(\operatorname{Cov}\left(\Delta c_{t, S}, R_{1 t, k, S}^{e}\right) \cdot \cdot \operatorname{Cov}\left(\Delta c_{t, S}, R_{N t, k, S}^{e}\right)\right)^{\top} .
$$


An investor would dislike an asset which the excess return has a positive covariance with the variation in the level of consumption. Such an asset pays less in bad states of the economy characterized by low future consumption level relative to the present, and the investor will require a relatively high premium for holding that asset. On the other hand, the investor will dislike the asset $i_{2}$ more than the asset $i_{1}$ in a situation where both covariances are positive, and the covariance of asset $i_{1}$ has the low magnitude. All other things being equal, asset $i_{2}$ will have a more higher required level risk premium than asset $i_{1}$.

By a similar reasoning, an investor would prefer an asset which the excess return has a negative covariance with the variation in the level of consumption. Such an asset pays more in bad states of the economy characterized by low future consumption level relative to the present, and the investor will be able to give up a relatively high premium for holding that asset. On the other hand, the investor will prefer the asset $i_{1}$ more than the asset $i_{2}$ in a situation where both covariances are negative, and the covariance of asset $i_{1}$ has the high magnitude. All other things being equal, asset $i_{2}$ will have a more lower given up level risk premium than asset $i_{1}$.

Let $h_{t}$ denotes the volatility of aggregate consumption. The second factor denoted:

$$
\Delta h_{t, S}=h_{t+S}-h_{t}=\sum_{j=1}^{S} \Delta h_{t+j}
$$

is the change in the volatility of consumption between the end and the beginning of the investment period. By similarity with the consumption level case, we define its covariance with an asset return as the $S$-volatility risk of the asset. The $S$-horizon volatility variation is relevant if investors have concerns about long-run risks in consumption volatility. Furthermore, if consumption level reacts with lags to returns, to some extent it should also be the case for consumption volatility. In this case, as $S$ increases, the $S$-volatility risk would provide the better measure of the volatility risk embodied in asset payoffs. The innovation of this paper is to show that, in addition to long-horizon consumption growth, long-horizon variation in consumption volatility captures the cross-sectional dispersion of stock returns as well, and that long-run volatility risk is economically important even in the presence of long-run consumption risk. For a given $S$, the cross-section of $S$-volatility risks for $k$-period holding stocks is defined by the vector:

$$
\operatorname{Cov}\left(\Delta h_{t, S}, R_{\cdot t, k, S}^{e}\right)=\left(\operatorname{Cov}\left(\Delta h_{t, S}, R_{1 t, k, S}^{e}\right) \cdot \cdot \cdot \operatorname{Cov}\left(\Delta h_{t, S}, R_{N t, k, S}^{e}\right)\right)^{\top} .
$$

An agent who faces an increase in macroeconomic uncertainty would fear the repercussion on its future wealth and then, he would like to increase precautionary savings. This investor would 
dislike an asset which the excess return has a negative covariance with the variation in the volatility of consumption. Such an asset pays less in bad states of the economy characterized by high future consumption volatility relative to the present, and the investor will require a relatively high premium for holding that asset. On the other hand, the investor will dislike the asset $i_{2}$ more than the asset $i_{1}$ in a situation where both covariances are negative, and the covariance of asset $i_{1}$ has the low magnitude. All other things being equal, asset $i_{2}$ will have a more higher required volatility risk premium that asset $i_{1}$.

By a similar reasoning, an investor would prefer an asset which the excess return has a positive covariance with the variation in the volatility of consumption. Such an asset pays more in bad states of the economy characterized by high future consumption volatility relative to the present, and the investor will be able to give up a relatively high premium for holding that asset. On the other hand, the investor will prefer the asset $i_{1}$ more than the asset $i_{2}$ in a situation where both covariances are positive, and the covariance of asset $i_{1}$ has the high magnitude. All other things being equal, asset $i_{2}$ will have a more lower given up volatility risk premium that asset $i_{1}$.

At this stage, $S$-volatility risks cannot be computed since consumption volatility is unobservable. To measure this risk from the data, we use a parametric measure of consumption volatility provided by a GARCH of Heston and Nandi (2000) with no leverage parameter. That is, we extract consumption volatility from the following dynamics:

$$
\begin{aligned}
\Delta c_{t+1} & =\mu_{c}+\sqrt{h_{t}} \epsilon_{t+1} \\
h_{t+1} & =\left(1-\phi_{h}\right) \mu_{h}+\phi_{h} h_{t}+\sigma_{h}\left(\epsilon_{t+1}^{2}-1\right)
\end{aligned}
$$

where $\epsilon_{t+1} \sim \mathcal{N} \mathcal{I D}(0,1)$. We further denote by $\pi$ the vector $\pi=\left(\mu_{c}, \mu_{h}, \phi_{h}, \sigma_{h}\right)^{\top}$ and let $\omega_{h}=\left(1-\phi_{h}\right) \mu_{h}-\sigma_{h}$.

We simply assume a constant expected consumption growth as in Tauchen (2005) since our aim is mostly to capture risks from consumption volatility. In affine general equilibrium models, every state variable that enters into the dynamics of consumption growth usually appears in the stochastic discount factor as a potentially priced factor. It is the case of the timevarying expected consumption growth in the Bansal and Yaron (2004)'s model. We will further check that extracting consumption volatility from an alternative specification which allows for time-varying expected consumption growth has a little influence in parameter estimates of the volatility dynamics. We have also assume that expected consumption growth is constant in our specification since it is likely to capture similar long-run risks in consumption level 
that are already captured by long-horizon consumption growth. ${ }^{3}$ We could have also specified expected consumption growth as linear in consumption volatility to continue to deal with macroeconomic uncertainty only, but this will not change either our method or subsequent results.

We compute empirical volatility risk factors $\Delta h_{t, S}(\widehat{\pi})$ from the recursion:

$$
\begin{aligned}
h_{0}(\widehat{\pi}) & =\widehat{\mu}_{h} \\
\forall t \geq 0, \quad h_{t+1}(\widehat{\pi}) & =\left(1-\widehat{\phi}_{h}\right) \widehat{\mu}_{h}+\widehat{\phi}_{h} h_{t}(\widehat{\pi})+\widehat{\sigma}_{h}\left[\frac{\left(\Delta c_{t+1}-\widehat{\mu}_{c}\right)^{2}}{h_{t}(\widehat{\pi})}-1\right]
\end{aligned}
$$

where $\widehat{\pi}$ is a consistent estimator of $\pi$.

We measure the risk-return relationship at each investment horizon $S$ and for each stock holding period $k$, through cross-sectional correlations between the vector (2.2) of $k$-period stock risk premia and the vectors of $S$-level and $S$-volatility risks, (2.3) and (2.4) respectively. These cross-sectional correlations are denoted:

$$
\begin{aligned}
& \rho_{r c}(S, k)=\operatorname{Corr}\left(E\left[R_{\cdot t, k, S}^{e}\right], \operatorname{Cov}\left(\Delta c_{t, S}, R_{\cdot t, k, S}^{e}\right)\right) \\
& \rho_{r h}(S, k)=\operatorname{Corr}\left(E\left[R_{\cdot t, k, S}^{e}\right], \operatorname{Cov}\left(\Delta h_{t, S}, R_{\cdot t, k, S}^{e}\right)\right)
\end{aligned}
$$

According to the theory, the average return of an asset is higher the more positively it covariates with variations in consumption level, and the more negatively it covariates with variations in consumption volatility. Moreover, the more negatively asset payoff covariates with variations in consumption level, and the more positively it covariates with variations in consumption volatility, the lower will be the asset risk premium. Thus, $\rho_{r c}(S, k)$ and $\rho_{r h}(S, k)$ are expected to be respectively positive and negative, and their magnitudes will assess how important are relationships between $k$-period holding stock returns and $S$-horizon variations in consumption level and in consumption volatility respectively.

Since the square of the correlation between the explained and the explicative variables measures the R-squared of the projection of the former onto the latter, we note that $\left[\rho_{r h}(S, k)\right]^{2}$ also measures the proportion of variations in risk premium across stocks, which is explained solely by consumption volatility risk. Similarly, $\left[\rho_{r c}(S, k)\right]^{2}$ also measures the proportion of variations in risk premium across stock, which is explained solely by consumption level risk.

\footnotetext{
${ }^{3}$ Note that expected consumption growth is usually empirically proxied by a weighted combination of the lags of consumption growth (see also Bansal, Dittmar and Lundblad (2004)), for example if consumption growth is an $\operatorname{ARMA}(1,1)$.
} 


\section{Data and Empirical Facts}

\subsection{Data}

We use return data constituted with four groups of 5 portfolios sorted on dividend yield, bookto-market, earnings-to-price, and cash flows-to-price ratios, as well as the 25 Fama and French size and book-to-market sorted portfolios. Returns are monthly and span the period 1946:4 to 2005:8. They are aggregated to obtain quarterly returns. The attractiveness of these sets of portfolios in empirical studies comes from that stocks show significant differences in their average excess returns. Table 1 shows the size and value premia across portfolios sorted from growth to value and from small to large.

In this paper, we will further be interested in the behavior of dividend shares of consump-

\section{Table 1: Mean One-Quarter Excess Returns for Portfolios Sorted on Various Di-} mensions: 1963:3-1999:4.

This table presents mean quarterly one-period stock returns in excess on the risk-free rate, for 5 portfolios sorted on book-to-market, dividend-to-price, earnings-to-price and cash flow-to-price in Panel A, and for the 25 Fama and French size and book-to-market portfolios in Panel B. Values are in percentage.

\begin{tabular}{|c|c|c|c|c|c|c|}
\hline & \multicolumn{6}{|c|}{ Panel A. 5 Valuation Ratio Sorted Portfolios } \\
\hline & Low & 2 & 3 & 4 & High & High-Low \\
\hline $\mathrm{B} / \mathrm{M}$ & 1.34 & 1.60 & 1.77 & 2.22 & 2.61 & 1.27 \\
\hline $\mathrm{D} / \mathrm{P}$ & 1.61 & 1.73 & 1.74 & 1.87 & 1.98 & 0.37 \\
\hline $\mathrm{E} / \mathrm{P}$ & 1.16 & 1.53 & 1.58 & 2.42 & 2.66 & 1.50 \\
\hline \multirow[t]{3}{*}{$\mathrm{CF} / \mathrm{P}$} & 1.29 & 1.54 & 1.79 & 1.92 & 2.58 & 1.29 \\
\hline & \multicolumn{6}{|c|}{ Panel B. 25 FF Size and B/M Sorted Portfolios } \\
\hline & Low & 2 & 3 & 4 & High & High-Low \\
\hline Small & 1.07 & 2.69 & 2.83 & 3.43 & 3.84 & 2.76 \\
\hline 2 & 1.44 & 2.18 & 2.94 & 3.09 & 3.35 & 1.91 \\
\hline 3 & 1.45 & 2.33 & 2.31 & 2.72 & 3.28 & 1.83 \\
\hline 4 & 1.74 & 1.64 & 2.33 & 2.69 & 2.81 & 1.07 \\
\hline Large & 1.33 & 1.47 & 1.51 & 1.73 & 1.82 & 0.50 \\
\hline Large-Small & -0.26 & 1.22 & 1.32 & 1.70 & 2.02 & \\
\hline
\end{tabular}


tion from the latter set of portfolios. For each portfolio, quarterly price and dividend series are constructed in the same manner as in Bansal, Dittmar and Lundblad (2005). We observe the monthly return series ${ }^{4}$ computed with and without dividend, $R_{t+1}^{\text {with }}$ and $R_{t+1}^{\text {wout }}$. Asset price and dividend series are then computed as:

$$
\begin{aligned}
& P_{t+1}=R_{t+1}^{\text {wout }} P_{t} \\
& D_{t+1}=\left(R_{t+1}^{\text {with }}-R_{t+1}^{\text {wout }}\right) P_{t},
\end{aligned}
$$

with $P_{0}=1$. Since the initial price was normalized to 1 , these measures represent the actual price and dividend up to a multiplicative constant. Monthly prices are averaged within each quarter to obtain quarterly prices and monthly dividends are summed within each quarter to obtain quarterly dividends. There is no evidence of a seasonal component in quarterly prices. On the contrary, quarterly dividends have strong seasonalities that are removed by taking as measure of dividends in quarter $t$, an average of the dividends in quarter $t$ and over the previous three quarters $t-3, t-2$ and $t-1$.

We also use quarterly data for consumption of nondurable and services from 1947:1 to 2005:2, taken from the NIPA tables available from the Bureau of Economic Analysis. Return, price and dividend series are converted into real using the associated PCE deflator. Dividendprice ratios are then computed. Annualized empirical means and standard deviations for excess returns, dividend growths and dividend-price ratios of the 25 Fama and French size and book-to-market sorted portfolios as well as for the market return, the risk-free rate and the consumption growth are shown in Table 2. Each label SxBy in the table represents one portfolio. The first digit $\mathbf{x}$ refers to the size quintiles ( 1 indicating the smallest firms, 5 the largest), and the second digit $\mathbf{y}$ refers to book-to-market quintiles (1 indicating the portfolio with the lowest book-to-market ratio, 5 the highest). Log shares are also constructed as the log ratio of dividend to consumption and represent the actual shares up to an additive constant. The pattern of these log shares are plotted in Figure 1.

To establish the observed facts between returns and volatility factors, we estimate the Heston and Nandi (2000) GARCH(1,1) for consumption growth. The longest sample period for quarterly consumption growth that we consider spans the second quarter of 1947 to the second quarter of 2005. We show results for the entire sample and those for a subsample starting in 1963:3 considered in previous works. Table 3 displays result for estimations over the two subsamples under study. The GARCH and ARCH coefficients of the dynamics are both significant and corroborate the central assumption that consumption volatility is time-varying.

\footnotetext{
${ }^{4}$ We take return data from: http://mba.tuck.dartmouth.edu/pages/faculty/ken.french/
} 
Table 2: Descriptive Statistics for Size and Book-to-Market Sorted Portfolios.

This table presents the annualized descriptive statistics of asset returns from 1963:3 to 2005:2. mean and standard deviation of excess returns and dividend-price ratios are in are in percentage.

\begin{tabular}{rrrrrrr} 
& \multicolumn{5}{c}{$1963: 3-2005: 2$} \\
\hline Asset & $E\left[R^{e}\right]$ & $\sigma\left[R^{e}\right]$ & $E[\Delta d]$ & $\sigma[\Delta d]$ & $E\left[\frac{D}{P}\right]$ & $\sigma\left[\frac{D}{P}\right]$ \\
\hline S1B1 & $(2)$ & $(3)$ & $(4)$ & $(5)$ & $(6)$ & $(7)$ \\
S1B2 & 11.04 & 28.13 & -5.54 & 29.26 & 0.60 & 0.46 \\
S1B3 & 11.65 & 24.42 & 5.65 & 14.70 & 2.00 & 0.96 \\
S1B4 & 14.18 & 22.97 & 7.37 & 16.16 & 2.35 & 1.04 \\
S1B5 & 15.89 & 25.42 & 9.74 & 21.88 & 1.95 & 0.93 \\
S2B1 & 6.00 & 26.46 & -2.96 & 38.58 & 0.99 & 0.63 \\
S2B2 & 8.97 & 21.36 & 2.58 & 14.78 & 2.03 & 1.02 \\
S2B3 & 11.79 & 20.83 & 5.02 & 12.61 & 2.72 & 1.19 \\
S2B4 & 12.64 & 20.63 & 4.93 & 13.82 & 3.33 & 1.39 \\
S2B5 & 13.88 & 21.04 & 7.22 & 20.00 & 2.92 & 1.29 \\
S3B1 & 6.02 & 23.12 & -0.99 & 19.53 & 1.27 & 0.75 \\
S3B2 & 9.57 & 19.43 & 3.21 & 14.35 & 2.32 & 1.11 \\
S3B3 & 9.40 & 17.40 & 3.12 & 14.84 & 3.22 & 1.34 \\
S3B4 & 11.21 & 19.66 & 4.99 & 12.73 & 3.76 & 1.50 \\
S3B5 & 13.48 & 20.07 & 6.79 & 19.78 & 3.64 & 1.42 \\
S4B1 & 7.15 & 20.38 & 1.06 & 26.19 & 1.62 & 0.77 \\
S4B2 & 6.76 & 17.17 & 0.85 & 18.14 & 2.73 & 1.13 \\
S4B3 & 9.40 & 16.51 & 4.17 & 16.58 & 3.53 & 1.44 \\
S4B4 & 11.14 & 18.31 & 3.46 & 13.99 & 4.20 & 1.57 \\
S4B5 & 11.57 & 18.62 & 5.16 & 12.19 & 3.96 & 1.38 \\
S5B1 & 5.61 & 18.00 & 2.51 & 11.64 & 2.14 & 0.81 \\
S5B2 & 6.06 & 15.47 & 1.93 & 11.90 & 3.34 & 1.18 \\
S5B3 & 6.32 & 14.44 & 1.29 & 7.70 & 4.06 & 1.52 \\
S5B4 & 7.22 & 15.16 & 0.90 & 10.50 & 4.65 & 1.73 \\
S5B5 & 7.73 & 18.12 & 0.45 & 17.02 & 4.89 & 1.87 \\
\hline MKT & 6.10 & 16.14 & & & & \\
RF & 1.79 & 1.14 & & & & \\
CONS & & & 2.22 & 1.32 & & \\
\hline & & & & & &
\end{tabular}

Bansal, Khatchatrian and Yaron (2004) estimate a standard $\operatorname{GARCH}(1,1)$ for consumption growth and find similar conclusions. 


\section{Table 3: Heston and Nandi (2000) GARCH(1,1) Fit of Consumption Growth.}

This table presents results for the estimation of model (2.6) for the two samples. In panels A1 and B1, all four parameters of the model are estimated. In panels A2 and B2, only three parameters are estimated because we use the variance targeting to determine the other (we set the parameter $\mu_{h}$ to the sample value of the variance of consumption growth).

\begin{tabular}{llccc}
\hline & \multicolumn{1}{c}{$\mu_{c}$} & $\mu_{h}$ & $\phi_{h}$ & $\sigma_{h}$ \\
$(1)$ & \multicolumn{1}{c}{$(2)$} & $(3)$ & $(4)$ & $(5)$ \\
\cline { 2 - 5 } & A1. Sample 1947:2 & $2005: 2$ \\
Estimate & 0.00544 & $2.698 \mathrm{E}-5$ & 0.87552 & $4.430 \mathrm{E}-6$ \\
Std.dev. & 0.00031 & $5.888 \mathrm{E}-6$ & 0.05799 & $1.340 \mathrm{E}-6$ \\
& A2. Sample 1947:2 $-2005: 2$ & (variance targeting) \\
Estimate & 0.00544 & $2.544 \mathrm{E}-5$ & 0.87357 & $4.206 \mathrm{E}-6$ \\
Std.dev. & 0.00031 & & 0.05820 & $0.987 \mathrm{E}-6$ \\
& B1. Sample 1963:3 - 2005:2 \\
Estimate & 0.00568 & $1.954 \mathrm{E}-5$ & 0.82368 & $3.502 \mathrm{E}-6$ \\
Std.dev. & 0.00034 & $4.308 \mathrm{E}-6$ & 0.09328 & $1.202 \mathrm{E}-6$ \\
& B2. Sample 1963:3 - 2005:2 (variance targeting) \\
Estimate & 0.00568 & $1.909 \mathrm{E}-5$ & 0.82261 & $3.415 \mathrm{E}-6$ \\
Std.dev. & 0.00034 & & 0.09345 & $0.839 \mathrm{E}-6$ \\
\hline
\end{tabular}

We use parameter estimates and the extracted consumption volatility to compute estimates of the demeaned consumption and volatility factors. Following Parker and Julliard (2005), we stop the sample of returns at 1999:4, so that the horizon $S$ in consumption and volatility factors can vary up to five years while maintaining the same sample of returns for the study as we vary $S$. That is, we use all available consumption and volatility data up to the fourth quarter of 1999 plus $S$ quarters, with $S=23$ corresponding to the second quarter of 2005. For each stock, we compute sample covariances between factors and returns. As these covariances measure risks across assets, we compute the cross-sectional correlation of each risk with average excess return across the 25 Fama and French size and book-to-market sorted portfolios, in order to see if high excess returns are associated with high volatility risks. As discussed previously, the square of the correlation also measures the fraction of the cross-sectional dispersion in mean average excess returns explained by level or volatility risk.

We plot the pattern of $S$-level and $S$-volatility risks across book-to-market sorted portfolios, 
and also across dividend-to-price, earnings-to-price and cash flows-to-price sorted portfolios. The figures are similar to those of Hansen, Heaton and Li (2005) which show the pattern of $S$-level risk across 5 dividend-to-price sorted portfolios especially when the stock holding period is one quarter. Next, we describe how consumption level and consumption volatility risks are correlated with short and long-period returns, and analyse the pattern of these risks across value and growth portfolios.

\subsection{Patterns of $S$-level and $S$-volatility Risks}

In this subsection, we describe the pattern of consumption volatility risk across stocks. As $S$ varies, we describe how $S$-volatility risk ranks portfolios from the less to the more riskier, and we compare this ranking to that based on the risk premium. We also compare the ranking by consumption volatility risk to the ranking by consumption level risk. We focus on one-period $(k=1)$ and full period $(k=S)$ returns as this makes our findings comparable to results of previous studies (Parker and Julliard (2005), Bansal, Dittmar and Kiku (2005)). We will say that volatility or level risk rank stocks well if the more riskier is a portfolio, the more higher is its volatility or level risk.

Figure 2 shows the pattern of consumption volatility risk by investment horizon when stocks are hold for one quarter at the beginning of the investment period. At each investment horizon, the top point represents the less riskier stock and the bottom point the more riskier. It can be obseved that difference between volatility risks for the extreme value and the extreme growth portfolios is not apparent for $S=1$ and $S=2$. However, for $S>2$, there is a significant gap between volatility risks of these portfolios, with the value line on the bottom and the growth line on the top, which shows that value assets are more riskier than growth assets when investments are exposed to variations in consumption volatility. Because value stocks covariate highly and negatively with variations in the volatility of aggregate consumption and more so than other stocks, this means that their payoffs are lower than those of other stocks when macroeconomic uncertainty becomes higher in the future relatively to the present. Then value stocks are disliked more than other stocks and investors require a more higher premium to hold them. Not surprisingly in Figure 2, the market risk (covariance between aggregate stock market return and variations in consumption volatility) lies between extreme risks (value risk and growth risk).

Figure 3 shows the pattern of consumption level risk by investment horizon when stocks

are hold for one quarter at the beginning of the investment period. Contrarily to the pattern of 
consumption volatility risk across stocks, at each investment horizon, the top point represents the more riskier stock and the bottom point the less riskier. Compare to the pattern of consumption volatility risk, on can observe that for smaller investment horizons where volatility risk sorts stocks as they are ordered according to risk premium, level risk does worst in this sort. Growth assets appear to be more riskier than other assets when exposed to relatively short variations in consumption level, and this clearly appears for $S<6$ in Figure 3. However, consistent with a similar pattern plotted in Hansen, Heaton and Li (2005) and with the results of Parker and Julliard (2005), as the investment horizon increases, differences in consumption level risk across stocks become significant, with portfolios ranked as they are sorted according to their risk premium, that is value stocks are more riskier than growth stocks when investment are exposed to long-horizon variations in consumption level.

Figure 4 shows the pattern of consumption volatility risk by investment horizon when stocks are hold for the full investment period. This pattern clearly shows that the ranking between asset risks is the same between assets as the horizon increases, value stocks having a more pronounced negative covariance with volatility variations than growth stocks. Once again and not surprisingly, the long-horizon market portfolio risk lies between extreme portfolio risks. Since value stocks also have higher mean returns than growth stocks, one can expect that projecting full period stock returns in stock $S$-volatility risks will give a negative slope coefficient.

Figure 5 shows the pattern of consumption level risk by investment horizon when stocks are hold for the full investment period. Compare to the similar pattern of volatility risk, on can observe that consumption level risk fails to well rank the semi-growth portfolio which in all dimensions is riskier than the extreme growth portfolio. In addition, the extreme growth appears to be more riskier than the medium in dividend-to-price and cash flow-to-price dimensions, and even more riskier than the semi-value in the dividend-to-price dimension.

We also plot the pattern of $S$-volatility and $S$-level risks for book-to-market sorted portfolios at a less aggregate level, that is when assets are first sorted according to the firm size, and then according to the firm book-to-market in each size group. Figures 9 and 11 show the pattern of consumption volatility risk for one-period $(k=1)$ and full period $(k=S)$ holding stock returns respectively. Figures 10 and 12 display similar patterns of consumption level risk. All confirm that the findings at the aggregate level also hold in each size group.

While the pattern of consumption volatility and consumption level risks across stocks inform how portfolios are ranked from the less to the more riskier (or from the less to the more preferred), we cannot still assess the strength of the relationship between these risks 
and the total risk premium that investors require to invest in stocks instead of the safe asset. Even if portfolios are well ranked by volatility risk at horizons $S_{1}$ and $S_{2}$, the strength of the relationship between risk premium and consumption volatility risk at these horizons can differ widely. In section 2 we defined this strength through cross-sectional correlations between risk and risk premium whose the analysis follows.

\subsection{Analyzing the Risk-Return Relationship}

This section examines cross-sectional correlations between risk premium and consumption

volatility risk. As $S$ varies for given $k$, we analyze the strength of the relationship between volatility risk and return at lower investment horizons to the strength at longer horizons. At each horizon, we also compare the relationship between volatility risk and return to the relationship between level risk and return. On the other hand, as $k$ varies for given $S$, we analyze the strength of the relationship between volatility risk and return, and also oppose volatility risk-return relationship to level risk-return relationship.

For the starting date 1963:3, Table 4 shows correlations between risk premium and consumption level and consumption volatility risks when both the total investment horizon $S$ and the stock holding period $k$ equal one and two quarters, then one, two, three, four and five years. The second column of the table measures how much one-period returns are correlated to variations in consumption volatility, but also in consumption level as in Parker and Julliard (2005). One can observe that one-period stock risk premium is weakly and positively correlated to one-horizon consumption volatility risk and this is not consistent with the theory that, when exposed to variations in consumption volatility, riskier investments should have higher average excess returns. Moreover, while volatility risk-return correlation becomes negative from the horizon of two quarters, it remains weak. However the volatility risk-return correlation grows as the investment horizon increases.

The second column of Table 4 also shows the known weak correlation between contemporaneous consumption risk (here the level risk at the horizon of one quarter) and risk premium. This correlation is 0.32 and means that contemporaneous consumption risk explains only about $10 \%$ of variations in average stock returns. The level risk-return correlation is still weak at the investment horizon of two quarters, then grows as the horizon increases. If the weak performance of shorter variations in consumption level to explain differences in average stock returns is due to the slow adjustment of consumption to returns as argue by Parker and Julliard (2005), then we argue that the same reason could explain why shorter variations 
Table 4: Correlations between Returns and consumption level and consumption volatility risks: 1963:3-1999:4.

This table presents correlations of the mean excess $k$-period returns on the 25 Fama and French portfolios with the $S$-level and $S$-volatility risks. Risks are computed as covariances of returns with factors. For each horizon $S$, the top line represents correlations with $S$-level risk and the bottom line shows correlations with $S$-volatility risk. Consumption volatility satisfies the Heston and Nandi (2000) dynamics specified in equation (2.6).

\begin{tabular}{rrrrrrrr}
\hline & \multicolumn{7}{c}{$k$} \\
\cline { 2 - 8 } & 1 & 2 & 4 & 8 & 12 & 16 & 20 \\
\hline 1 & 0.32 & & & & & & \\
& $\mathbf{0 . 2 3}$ & & & & & & \\
2 & 0.30 & 0.54 & & & & & \\
& $\mathbf{- 0 . 3 8}$ & $\mathbf{- 0 . 0 3}$ & & & & & \\
& & & & & & & \\
4 & 0.45 & 0.56 & 0.70 & & & & \\
& $\mathbf{- 0 . 7 7}$ & $\mathbf{- 0 . 7 4}$ & $\mathbf{- 0 . 7 6}$ & & & & \\
8 & 0.70 & 0.77 & 0.76 & 0.68 & & & \\
& $\mathbf{- 0 . 7 2}$ & $\mathbf{- 0 . 7 9}$ & $\mathbf{- 0 . 8 6}$ & $\mathbf{- 0 . 8 8}$ & & & \\
12 & 0.80 & 0.84 & 0.86 & 0.82 & 0.59 & & \\
& $\mathbf{- 0 . 6 8}$ & $\mathbf{- 0 . 7 0}$ & $\mathbf{- 0 . 8 2}$ & $\mathbf{- 0 . 8 7}$ & $\mathbf{- 0 . 8 8}$ & & \\
16 & 0.76 & 0.79 & 0.82 & 0.86 & 0.73 & 0.54 & \\
& $\mathbf{- 0 . 6 3}$ & $\mathbf{- 0 . 7 0}$ & $\mathbf{- 0 . 8 4}$ & $\mathbf{- 0 . 8 7}$ & $\mathbf{- 0 . 8 7}$ & $\mathbf{- 0 . 9 0}$ & \\
20 & 0.77 & 0.83 & 0.85 & 0.86 & 0.81 & 0.67 & 0.45 \\
& $\mathbf{- 0 . 5 0}$ & $\mathbf{- 0 . 5 3}$ & $\mathbf{- 0 . 7 2}$ & $\mathbf{- 0 . 8 4}$ & $\mathbf{- 0 . 8 4}$ & $\mathbf{- 0 . 9 1}$ & $\mathbf{- 0 . 8 9}$ \\
\hline
\end{tabular}

in consumption volatility also performs weakly in explaining differences across average stock returns.

The diagonal line of Table 4 measures how much full period returns are correlated to variations in consumption volatility, but also in consumption level as in Bansal, Dittmar and Kiku (2005). It shows that consumption volatility risk is highly and negatively correlated to full period stock risk premium, and so more than one-period stock risk premium. In contrast consumption level risk is more correlated to one-quarter stock risk premium than to full period stock risk premium. On the other hand, correlation of average excess $S$-period returns with $S$-volatility risk dominates that with $S$-level risk at all horizons $S>2$. Since the former is quite constant for all investment horizons, it seems that there is a stable long-run relationship 
between stock returns and variations in consumption volatility. A correlation of -0.88 would also mean that more than $75 \%$ of heterogeneity in average long-period stock returns come from the heterogeneity in their exposure to permanent movements in consumption volatility.

The latter facts are well shown in Figure 6 which plots consumption volatility risk-return relationship versus consumption level risk-return relationship for one-quarter and full period holding stocks. The figure shows that average one-quarter returns are more correlated to short-horizon volatility risk than to short-horizon level risk. While this correlation is greater than 0.75 with volatility risk for horizons $2<S<7$, it is smaller than 0.55 for level risk for the same horizons. In contrast, average one-period returns are more correlated to long-horizon consumption level risk than to long-horizon consumption volatility risk. With long-horizon consumption volatility risk, this correlation has a downward trend from the horizon $S=8$, where it is worth -0.72 , to the horizon $S=20$, where it is worth -0.50 . On the other hand, with long-horizon consumption level risk, this correlation is close to about 0.80 from the horizon $S=9$ to the horizon $S=20$, both of where it is worth 0.77 .

Figure 6 also confirms the result in Table 4 that average full period returns are more correlated to consumption volatility risk than to consumption level risk, with a complete domination of the volatility risk-return relationship in the long run. While the volatility-risk return correlation is close to about -0.90 from the horizon $S=7$ to the horizon $S=20$, the level risk-return relationship declines from 0.70 to 0.45 for the same horizons.

\section{Pricing Consumption Volatility Risk in the Cross-Section}

The striking pattern of $S$-volatility risk across stocks and its high correlation with expected excess returns motivates our investigation of how this risk is priced in financial markets, especially when $S$-level risk is also taken into account. We inquire how much of the crosssectional differences in stocks is explained by both $S$-level and $S$-volatility risks, and this is important since variations in consumption level are uncorrelated to variations in consumption volatility from our GARCH specification. Estimating the volatility risk price in a two-factor model, and evaluating the amount of premium coming from volatility variations will also determine how important are long-run volatility risks in the presence of long-run consumption risks.

We estimate the following two-factor model:

$$
E\left[R_{i t, k, S}^{e}\right]=b_{u, S}+p_{c, S} \operatorname{Cov}\left(\xi_{\Delta c, t, S}, R_{i t, k, S}^{e}\right)+p_{h, S} \operatorname{Cov}\left(\xi_{\Delta h, t, S}, R_{i t, k, S}^{e}\right)
$$


where $\xi_{\Delta c, t, S}=\Delta c_{t, S}-E\left[\Delta c_{t, S}\right]$ and $\xi_{\Delta h, t, S}=\Delta h_{t, S}-E\left[\Delta h_{t, S}\right]$ are respectively the demeaned $S$-horizon variations in consumption level and in consumption volatility. The constant $b_{u, S}$ is introduced to measure by how much the cross-sectional model fails to predict returns.

Equation (4.1) postulates that investors demand or give up both multihorizon consumption and volatility risk premia to invest in stocks. Each premium is the product of the quantity of the associated risk with a parameter that measures the price (or the compensation) for a unit risk. Since investors require a positive risk premium to hold assets that they dislike and are able to require a negative risk premium (give up a positive risk premium) to hold asset that they prefer as discussed in Section 2, from an economic point of view, the price of the volatility risk should therefore be negative and the price of the level risk positive. Intuitively, the coefficients $p_{c, S}$ and $p_{h, S}$ are expected to be positive and negative respectively. This section provides details for estimating $S$-level and $S$-volatility risk prices in the twofactor cross-sectional linear covariance model (4.1). It then analyzes the estimation results and provides some conclusions.

Parker and Julliard (2005) assume an investor whose the intertemporal marginal rate of substitution depends solely on the level of consumption and they essentially investigate crosssectional relations like (4.1), with $k=1$ and without $S$-volatility risk. Bansal, Dittmar and Kiku (2005) also deal with similar cross-sectional relations which do not involve $S$-volatility risk, but in the case $k=S$. However, they decompose the $S$-level risk into a trend risk and a business cycle risk, which they show are compensated by appropriate multiperiod returns. In addition, since the volatility of aggregate consumption varies in relation with the business cycle, as stated in Kandel and Stambaugh (1990), it could be said that the $S$-horizon variation in consumption volatility appears to be a business cycle risk factor, as well as the $S$-horizon variation in consumption level as shown in Parker and Julliard (2005).

\subsection{Estimation Methodology}

Following recent empirical studies of cross-sectional asset pricing (see for example, Cochrane (1996), Jagannathan and Wang (1996), and Jacobs and Wang (2004)), we use the generalized method of moment (GMM, Hansen (1982)) to evaluate the significance of consumption volatility factors. Cochrane (2001, Chapter 15) demonstrates that the GMM approach works well for linear asset pricing models. The cross-sectional model (4.1) satisfies a moment condition of the form:

$$
E\left[-\iota b+\left(1-\xi^{\top}(\pi) p\right) R\right]=0
$$


where $\xi(\pi)$ is the vector of demeaned factors, $R$ is the vector of excess returns, $p$ is the vector of risk prices and $b$ is the constant term. Demeaned factors depend on the parameter vector $\pi$ that govern the processes (2.5) and (2.6) of consumption growth and consumption volatility. The vector $\iota$ is of same length as $R$ and has all its components equal to one. The moment condition (4.2) holds for a given date and a given horizon. We avoid subscripts in variables and parameters to simplify notations in this section. The vectors $\xi(\pi)$ and $p$ have two components each other.

Equation (4.2) is also equivalent to:

$$
\mu_{R}=\iota b+\Sigma_{R \xi}(\pi) p
$$

where $\mu_{R}=E[R]$ and $\Sigma_{R \xi}(\pi)=E\left[R \xi^{\top}(\pi)\right]$ are respectively the vector of mean excess returns and the covariance matrix of excess returns with factors. The latter depends on the parameter vector $\pi$ of consumption and volatility processes through $\xi(\pi)$.

Two-Step Estimation With Prespecified Weighting Matrix. If the parameter vector $\pi$ were known, then the constant $b$ and the factor risk prices $p$ could be consistently estimated by GMM based on the moment condition (4.2), by minimizing the distance between average actual returns $\widehat{\mu}_{R}$ and average predicted returns $\iota b+\widehat{\Sigma}_{R \xi}(\pi) p$ with respect to a positive definite matrix $W . \widehat{\mu}_{R}$ and $\widehat{\Sigma}_{R \xi}(\pi)$ are the sample counterparts of the mean vector $\mu_{R}$ and the covariance matrix $\Sigma_{R \xi}(\pi)$.

Minimizing the distance:

$$
\operatorname{dist}(b, p)=\sqrt{\left(\widehat{\mu}_{R}-\iota b-\widehat{\Sigma}_{R \xi}(\pi) p\right)^{\top} W\left(\widehat{\mu}_{R}-\iota b-\widehat{\Sigma}_{R \xi}(\pi) p\right)}
$$

with respect to $b$ and $p$ gives:

$$
\begin{aligned}
& \widehat{b}(\pi)=\left(\iota^{\top} W \iota\right)^{-1} \iota^{\top} W\left[\widehat{\mu}_{R}-\widehat{\Sigma}_{R \xi}(\pi) \widehat{p}(\pi)\right] \\
& \widehat{p}(\pi)=\left[\widehat{\Sigma}_{\xi R}(\pi) A \widehat{\Sigma}_{R \xi}(\pi)\right]^{-1} \widehat{\Sigma}_{\xi R}(\pi) A \widehat{\mu}_{R}
\end{aligned}
$$

where $A=W-W \iota\left(\iota^{\top} W \iota\right)^{-1} \iota^{\top} W$. For these solutions, the vector of pricing errors and the minimum distance value are given by:

$$
\begin{aligned}
\widehat{e}(\pi) & =W^{-1} \widehat{B}(\pi) \widehat{\mu}_{R} \\
\widehat{d}(\pi) & =\sqrt{\widehat{e}^{\top}(\pi) W \widehat{e}(\pi)}=\sqrt{\widehat{\mu}_{R}^{\top} \widehat{B}(\pi) \widehat{\mu}_{R}}
\end{aligned}
$$


where $\widehat{B}(\pi)=A-A \widehat{\Sigma}_{R \xi}(\pi)\left[\widehat{\Sigma}_{\xi R}(\pi) A \widehat{\Sigma}_{R \xi}(\pi)\right]^{-1} \widehat{\Sigma}_{\xi R}(\pi) A$. We then compute the adjusted central R-squared through the formula:

$$
R^{2}(\pi)=1-\frac{N-1}{N-K-1} \frac{\widehat{e}^{\top}(\pi) A \widehat{e}(\pi)}{\widehat{\mu}_{R}^{\top} A \widehat{\mu}_{R}},
$$

where $N$ and $K$ are respectively the number of portfolios and the number of factors. If $W$ is the identity matrix, then the formula (4.9) gives the adjusted central R-squared calculated as if we were doing a linear regression of the average returns on risks measured by covariances between returns and factors. In this case, $\widehat{d}(\pi) / \sqrt{N}$ is the square root of the weighted average of the squared pricing errors and measures how much the expected return based on the fitted model is off for a typical portfolio.

The matrices $A$ and $\widehat{B}(\pi)$ have the property that $A W^{-1} A=A$ and $\widehat{B}(\pi) W^{-1} \widehat{B}(\pi)=$ $\widehat{B}(\pi)$. Let $\widehat{\Sigma}_{b b}(\pi)$ and $\widehat{\Sigma}_{p p}(\pi)$ the variances of these estimators. In general, $\widehat{b}(\pi), \widehat{p}(\pi)$, $\widehat{\Sigma}_{b b}(\pi), \widehat{\Sigma}_{p p}(\pi), \widehat{e}(\pi)$ and $\widehat{d}(\pi)$ are continuous functions of $\pi$. Then, if $\pi$ is unknown and if $\widehat{\pi}$ is a consistent estimator of $\pi$, it will hold that $\widehat{b}(\widehat{\pi}), \widehat{p}(\widehat{\pi}), \widehat{\Sigma}_{b b}(\widehat{\pi})$ and $\widehat{\Sigma}_{p p}(\widehat{\pi})$ are also consistent estimates of $b, p, \Sigma_{b b}$ and $\Sigma_{p p}$. Even if this method of estimation is consistent, the uncertainty in the estimation of $\pi$ leads to a larger asymptotic variance than when $\pi$ is known. We have consistently estimated $\pi$ by maximum likelihood in Section 3 . We now use this estimate to compute the estimates $\widehat{b}=\widehat{b}(\widehat{\pi}), \widehat{p}=\widehat{p}(\widehat{\pi}), \widehat{\Sigma}_{b b}=\widehat{\Sigma}_{b b}(\widehat{\pi})$ and $\widehat{\Sigma}_{p p}=\widehat{\Sigma}_{p p}(\widehat{\pi})$, and also the pricing errors $\widehat{e}(\widehat{\pi})$, the minimum distance $\widehat{d}(\widehat{\pi})$ and the R-squared $R^{2}(\widehat{\pi})$.

One-Step Estimation With Prespecified Weighting Matrices. Let $f(\pi ; \Delta c)$ denotes the density function of $\epsilon$ in the model (2.6) satisfied by consumption growth and consumption volatility. In the two-stage estimation procedure, $L(\pi ; \Delta c)=\sum \ln f(\pi ; \Delta c)$ is first maximized to obtain an estimator of $\pi$ that is further plugged into the cross-sectional estimation to obtained estimates of factor risk prices. With the one-step estimation procedure, we estimate the parameter $\pi$, simultaneously with the cross-sectional factor risk prices in a full single-stage GMM system. Let $\ell(\pi)=\left(\xi^{\top}(\pi), \frac{\partial \ln f}{\partial \pi^{\top}}\right)^{\top}$. In addition to the moment condition (4.2) we consider the moment condition:

$$
E[\ell(\pi)]=0=\mu_{\ell}(\pi) .
$$

We perform the GMM estimation by placing the weighting matrices $W$ and $\lambda \widehat{\Sigma}_{\ell \ell}^{-1}(\pi)$ respectively on the moments (4.2) and (4.10), and a null matrix on any product of these moments. This one-step estimation can be seen as practically equivalent to the two-step estimation. In the first step, choose $\widehat{\pi}$ to minimize $\widehat{e}^{\top}(\pi) W \widehat{e}(\pi)+\lambda \widehat{\mu}_{\ell}^{\top}(\pi) \widehat{\Sigma}_{\ell \ell}^{-1}(\pi) \widehat{\mu}_{\ell}(\pi)$ where $\widehat{\mu}_{\ell}(\pi)$ is 
the sample counterpart of $\mu_{\ell}(\pi)$, and where $\widehat{e}(\pi)$ is defined as in (4.7). In the second step, plug $\widehat{\pi}$ into (4.5) and (4.6) to obtain $\widehat{b}$ and $\widehat{p}$. The number $\lambda$ is large enough to ensure that estimates fit well the consumption growth and volatility processes, match factor conditional or unconditional means, as well as minimize the gap between actual and fitted returns (See also Yogo (2005) and Parker and Julliard (2005)).

Choosing the Prespecified Weighting Matrix. As weighting matrix, we use the second moment matrix of returns $W=\widehat{\Sigma}_{R R}^{-1}$. Hansen and Jagannathan (1997) advocate the use of this matrix instead of the optimal weighting matrix. It has two main economically important features. First, it provides estimates that minimize the distance between a stochastic discount factor that depends in a simple linear way on variations in both consumption level and consumption volatility, and the space of true stochastic discount factors. Second, as well as the optimal weighting matrix, the second moment matrix will make the objective function (4.4) invariant to the initial choice of intertemporal portfolios. ${ }^{5}$ The portfolios used for the estimation are formed on economically interesting characteristics (size and book-to-market ratio). The second moment matrix will also form economically interesting combinations of these portfolios instead of unusual ones as the optimal matrix will do, and is more likely to provide small pricing errors (Cochrane 2001, Chap. 11).

The R-squared (4.9) when $W=\widehat{\Sigma}_{R R}^{-1}$ is not interpretable as explanatory power of initial stock risk premia by level and volatility risks. Risk-return correlations in Section 2 were computed giving each portfolio equal weight. For this reason, only the R-squared (4.9) based on the identity matrix $W=I$ that puts equal weight on initial portfolios, can be used to compare horizon-dependent models since they are all based on equally weighted pricing errors. This R-squared is interpretable in terms of explanatory power of level and volatility risks and is related to squared correlations between risk premium and risks, discussed in Section 3.

\subsection{Estimation Results}

This section will ask whether variations in consumption level and in consumption volatility are statistically significant, as well as if model tests of overindentifying restrictions reject the complete explanation of average stock returns by these factors. However, beyond these econometric issues, we are also and perhaps mostly interested in the economical significance of consumption level and consumption volatility risks for the cross-section of average stock

\footnotetext{
${ }^{5}$ Kandel and Stambaugh (1995) argue that results of several important asset pricing model tests are portfoliodependent.
} 
Table 5: Estimation of the price of the $S$-volatility risk in the Cross-Section of One-Period Stock Returns: 1963:3-1999:4.

This table presents results from the two-step estimation described in Section 3 and based on the weighting matrix $W=\widehat{\Sigma}_{R R}^{-1}$. The entries of the table are the total investment horizon $S$, the horizon $k$ of the investment in stocks, estimates of the constant term $\widehat{b}_{u, S}$, of the price of the $S$-level risk $\widehat{p}_{c, S}$ and of the price of the $S$-volatility risk $\widehat{p}_{h, S}$ (to be multiplied by $10^{-4}$ ), the model J-statistics $J_{T}$, the cross-sectional R-squared $R^{2}$ and the square root of the weighted average of square pricing errors $\widehat{d}(\pi)$. The two latter statistics are also provided for the identity weighting matrix, namely $R^{2}(I)$ and $\widehat{d}(I)$. The numbers below the estimates are standard errors and below the J-statistics is the p-value. Covariance matrices are calculated using the Newey-West procedure with $S$ lags.

\begin{tabular}{rrrrrrrrrr}
\hline$k$ & $S$ & $\widehat{b}_{u, S}$ & $\widehat{p}_{c, S}$ & $\widehat{p}_{h, S}$ & $J_{T}$ & $R^{2}$ & $\widehat{d}$ & $R^{2}(I)$ & $\widehat{d}(I)$ \\
\hline 1 & 1 & 1.90 & 13.09 & $\mathbf{3 . 4 3}$ & 60.52 & -0.08 & 0.69 & 0.11 & 0.54 \\
& & $(0.52)$ & $(37.82)$ & $\mathbf{( 3 . 5 1 )}$ & {$[0.000]$} & & & & \\
1 & 4 & 1.94 & 18.51 & $\mathbf{- 0 . 4 8}$ & 109.03 & -0.07 & 0.69 & 0.56 & 0.39 \\
& & $(0.66)$ & $(19.86)$ & $\mathbf{( 2 . 5 1 )}$ & {$[0.000]$} & & & & \\
1 & 8 & 2.06 & 9.87 & $\mathbf{- 1 . 5 8}$ & 146.40 & -0.06 & 0.69 & 0.50 & 0.42 \\
& & $(0.65)$ & $(13.54)$ & $\mathbf{( 2 . 2 5 )}$ & {$[0.000]$} & & & & \\
1 & 12 & 2.06 & 7.82 & $\mathbf{0 . 5 8}$ & 225.44 & -0.08 & 0.69 & 0.60 & 0.38 \\
& & $(0.68)$ & $(9.95)$ & $\mathbf{( 2 . 0 3 )}$ & {$[0.000]$} & & & & \\
1 & 16 & 2.12 & 6.86 & $\mathbf{0 . 2 3}$ & 282.95 & -0.08 & 0.70 & 0.63 & 0.38 \\
& & $(0.77)$ & $(10.92)$ & $\mathbf{( 2 . 0 8 )}$ & {$[0.000]$} & & & & \\
\hline
\end{tabular}

returns. This economical significance contains two major points. Are the prices of the consumption level and consumption volatility risks respectively positive and negative as will be expected from the facts established in Section 2 and consistently with the theory? Do these risks explain a sizable percentage of variation in average stock returns?

We perform the estimation of the cross-sectional linear covariance model (4.1) for five values of $S$, corresponding to investment horizons of one quarter, then one, two, three and four years $(S=1,4,8,12$ and 16$)$. We provide results for the estimation on the sample starting at 1963:3. We rely results based on two-step estimation since one-step estimation results are similar. These results are shown in Tables 5 and 6 . We report the R-squared based on the identity matrix as well as the associated minimum distance between actual and fitted returns. 
Table 5 shows that, both $S$-level and $S$-volatility risk prices are estimated insignificantly at all horizons, in the cross-section of one-period holding stock returns. Estimates of volatility risk price are even positive at horizons of three and four years. However, while consumption level and volatility risks appear not statistically significant, they show some economic significance in explaining the cross-section of average one-period stock risk premiums. Both of these risks explain $60 \%$ of variations in average one-period returns at the horizon of three years, and $63 \%$ of these variations at the horizon of four years. This percentage is $11 \%$ at the horizon of one quarter and reflects the well-documented weakness of contemporaneous consumption risk is explaining differences in stock returns. As discussed in Parker and Julliard (2005), the fact that the cross-sectional model does not perform as this horizon can be related to the low adjustment of consumption to returns. However, the fact that it behaves well for longer horizons, as we can see an increase in the R-squared from the horizon of one quarter, can not only be related to the fact that consumption and consequently volatility have had time to adjust to returns. It also reflects the concerns that investors have about long-run risks both in consumption level and in consumption volatility.

Table 6 shows that, both $S$-level and $S$-volatility risk prices are estimated significantly at longer horizons, in the cross-section of full-period holding stock returns. The price of the $S$-volatility risk is everywhere negative but the first horizon. Note from the diagonal of Table 4 that a positive rather than a negative correlation between volatility risk and return was reported for this horizon. Note also that the estimated magnitude of the price of volatility risk is almost the same for longer horizons. Consistent with the results of related studies the price of the $S$-level risk is almost everywhere positive and significantly estimated. Consumption level and consumption volatility risks explain $72 \%$ of variations in average full-period holding stock returns at the horizon of one year. This explanatory power increases for longer horizons and reaches $80 \%$ at the horizon of four years. Most of this variability may come from $S$ volatility risk since it is more correlated to long-period risk premia than $S$-level risk. The $\mathrm{RSSE}^{6}$, which also measures the distance between the vector of actual returns and the vector of fitted returns, increases from short to long horizons. It shows that the fitted one-period risk premium departs in average from the actual by $0.32 \%$ to $0.42 \%$ per quarter.

Estimated positive and negative signs for consumption level and consumption volatility risk respectively confirms that these risks are correctly priced, in the sense that portfolios with higher positive covariances of returns with variations in consumption level, and high negative covariances of returns with variations in consumption volatility, will have high average

\footnotetext{
${ }^{6}$ Root Sum Squared Errors
} 
Table 6: Estimation of the price of the $S$-volatility risk in the Cross-Section of Long-Horizon Stock Returns: 1963:3-1999:4.

This table presents results from the two-step estimation described in Section 3 and based on the weighting matrix $W=\widehat{\Sigma}_{R R}^{-1}$. The entries of the table are the total investment horizon $S$, the horizon $k$ of the investment in stocks, estimates of the constant term $\widehat{b}_{u, S}$, of the price of the $S$-level risk $\widehat{p}_{c, S}$ and of the price of the $S$-volatility risk $\widehat{p}_{h, S}$ (to be multiplied by $10^{-4}$ ), the model J-statistics $J_{T}$, the cross-sectional R-squared $R^{2}$ and the square root of the weighted average of square pricing errors $\widehat{d}(\pi)$. The two latter statistics are also provided for the identity weighting matrix, namely $R^{2}(I)$ and $\widehat{d}(I)$. The numbers below the estimates are standard errors and below the J-statistics is the p-value. Covariance matrices are calculated using the Newey-West procedure with $S$ lags.

\begin{tabular}{rrrrrrrrrr}
\hline$k$ & $S$ & $\widehat{b}_{u, S}$ & $\widehat{p}_{c, S}$ & $\widehat{p}_{h, S}$ & $J_{T}$ & $R^{2}$ & $\widehat{d}$ & $R^{2}(I)$ & $\widehat{d}(I)$ \\
\hline 1 & 1 & 1.90 & 13.09 & $\mathbf{3 . 4 3}$ & 60.52 & -0.08 & 0.69 & 0.11 & 0.54 \\
& & $(0.52)$ & $(37.82)$ & $\mathbf{( 3 . 5 1 )}$ & {$[0.000]$} & & & & \\
4 & 4 & 3.36 & 66.28 & $\mathbf{- 2 . 5 1}$ & 67.46 & 0.05 & 1.52 & 0.72 & 1.29 \\
& & $(2.74)$ & $(21.26)$ & $\mathbf{( 4 . 0 1 )}$ & {$[0.000]$} & & & & \\
8 & 8 & -2.52 & 37.85 & $\mathbf{- 5 . 9 1}$ & 75.74 & 0.04 & 2.51 & 0.76 & 2.89 \\
& & $(3.51)$ & $(17.52)$ & $\mathbf{( 2 . 2 9 )}$ & {$[0.000]$} & & & & \\
12 & 12 & -1.16 & 37.22 & $\mathbf{- 5 . 5 0}$ & 139.85 & 0.06 & 3.05 & 0.75 & 5.04 \\
& & $(2.67)$ & $(13.35)$ & $\mathbf{( 1 . 8 5 )}$ & {$[0.000]$} & & & & \\
16 & 16 & 12.84 & 28.78 & $\mathbf{- 5 . 2 1}$ & 198.95 & 0.00 & 3.96 & 0.80 & 6.67 \\
& & $(5.56)$ & $(10.65)$ & $\mathbf{( 2 . 1 3 )}$ & {$[0.000]$} & & & & \\
\hline
\end{tabular}

excess returns. Small $R^{2}$ s from the estimation based on $W=\widehat{\Sigma}_{R R}^{-1}$, mean that with respect to the square root of the second moment matrix, the combination of $S$-level risks and the combination of $S$-volatility risks across stocks are not economically important in explaining the combination of average stock returns. This highlights the fact that the cross-sectional $R^{2}$ and the corresponding distance between actual and fitted returns are not invariant to portfolio formation (Cochrane (2006), Roll and Ross (1994), Kandel and Stambaugh (1995)) and depend a lot on the estimation method. ${ }^{7}$ However, this does not change the fact that $S$-level risk and $S$-volatility risks themselves are economically important in explaining the cross-section of average stock returns.

\footnotetext{
${ }^{7} R^{2}$ is only well-defined for the estimation with the identity weighting matrix when estimates are equivalent to OLS estimates.
} 
The constant term is generally insignificant in all models with $k=S$. The $J$-statistics for the different estimation exercises vary widely. While it is tempting to interpret these differences, such an interpretation is not possible since the model at a given horizon does not nest that of the previous or the next horizon. We can only conclude that almost all test statistics indicate rejection of the null hypothesis at conventional levels of significance.

\section{$5 \quad$ Interpreting the Empirical Evidence}

We have shown previously that empirical facts support the evidence of a long-run consumption volatility pricing factor in the cross-section of stock returns. In this section, we show that this empirical evidence is consistent with the implications of existing parametric general equilibrium models. We construct an economy where agents have concern about both consumption level and consumption volatility, where associated risks carry observed price signs and magnitudes and where value stocks are more riskier than growth stocks according to consumption volatility risk. To achieve this aim, we follow the literature that assumes a long-term investor with recursive preferences (Kreps and Porteus (1978), Epstein and Zin (1989) and Weil (1990)) and specify the dynamics of economic endowments. We then calibrate the model so that portfolio returns and other statistics are similar to their actual counterparts and study its implications for the cross-section of stock returns.

\subsection{The Model of the Economic Behavior}

The current continuation value of investor's utility evolves according to:

$$
\begin{aligned}
V_{t} & =\left\{(1-\delta) C_{t}^{1-\frac{1}{\psi}}+\delta\left[\mathcal{R}_{t}\left(V_{t+1}\right)\right]^{1-\frac{1}{\psi}}\right\}^{\frac{1}{1-\frac{1}{\psi}}} \quad \text { if } \psi \neq 1 \\
& =\left[C_{t}\right]^{1-\delta}\left[\mathcal{R}_{t}\left(V_{t+1}\right)\right]^{\delta} \quad \text { if } \psi=1,
\end{aligned}
$$

where $\mathcal{R}_{t}\left(V_{t+1}\right)=\left[E\left(V_{t+1}^{1-\gamma}\right) \mid \mathcal{J}_{t}\right]^{\frac{1}{1-\gamma}}$ and $\mathcal{J}_{t}$ is the whole information set of the investor at time $t$. The parameter of risk aversion is $\gamma$, the elasticity of intertemporal substitution (EIS) is $\psi$, the subjective discount factor is $\delta$ and the parameter $\theta \equiv(1-\gamma)\left(1-\psi^{-1}\right)^{-1}$ helps for many interpretations. Epstein and Zin (1989) show that for such an investor, consumption and portfolio choice induces a restriction on the gross return on any asset $i$ that is given by the Euler equation:

$$
E\left[M_{t, t+1} R_{i, t+1} \mid \mathcal{J}_{t}\right]=1,
$$


where $M_{t, t+1}$ is the standard SDF that values consumption as well as any financial payoff one period ahead and is given by:

$$
M_{t, t+1}=\left[\delta\left(\frac{C_{t+1}}{C_{t}}\right)^{-\frac{1}{\psi}}\right]^{\theta}\left(\frac{1}{R_{w, t+1}}\right)^{1-\theta} .
$$

$R_{w, t+1}$ is the gross return to the total consumption claim. The logarithm of the Epstein-Zin $\mathrm{SDF}$ is given by:

$$
m_{t, t+1}=\theta \ln \delta-\frac{\theta}{\psi} \Delta c_{t+1}-(1-\theta) r_{w, t+1},
$$

where $r_{w, t+1}=\ln R_{w, t+1}$. The log-linearization of the investor's budget constraint, defined by the Campbell and Shiller (1988)'s approximation of the log-return around a suitable benchmark is:

$$
r_{w, t+1}=\rho_{0}+\frac{1}{\rho_{1}} x_{t}-x_{t+1}+\Delta c_{t+1},
$$

where $x_{t}=\ln C_{t}-\ln W_{t}$ is the $\log$ consumption-wealth ratio. ${ }^{8}$

The standard SDF of the power utility does not depend on consumption volatility even if consumption growth dynamics contains time-varying volatility. It only depends on the level of consumption growth. On the contrary, an investor with recursive preferences cares about consumption volatility. For such an investor, the intertemporal marginal rate of substitution depends on consumption valuation ratios whose movements can be related to that of consumption volatility (see Bansal, Khatchatrian and Yaron (2004)).

According to (5.4), since consumption growth is observable and the return to total wealth is not, any state variable that is suspected to have a power to price asset returns and consistently with the general equilibrium framework should be linked to the unobservable return. In order to establish this link, researchers assume that equilibrium consumption together with such state variables follow an exogenous model. Here consumption growth follows the following dynamics:

$$
\begin{aligned}
\Delta c_{t+1} & =\mu_{c}+\sqrt{h_{t}} \epsilon_{t+1} \\
h_{t+1} & =\left(1-\phi_{h}\right) \mu_{h}+\phi_{h} h_{t}+\sigma_{h} \eta_{t+1},
\end{aligned}
$$

where $\left(\epsilon_{t+1}, \eta_{t+1}\right)^{\top} \sim \mathcal{N}$. I.D $(0, I)$. The gaussian dynamics $(5.7)$ for the volatility of aggregate consumption is also considered by Bansal and Yaron (2004). It is more tractable for analytical

\footnotetext{
${ }^{8}$ The constant $\rho_{0}$ is given by:

$$
\rho_{0}=\ln \left(\frac{1-\rho_{1}}{\rho_{1}}\right)-\frac{\ln \left(1-\rho_{1}\right)}{\rho_{1}} .
$$
}


issues than the squared root dynamics found in Tauchen (2005). Moreover, it is more closed to the GARCH specification (2.6) used in Section 2 for empirical purposes (constant volatility of volatility for example).

Since shocks to consumption and consequently to total investor's wealth and its marginal rate of substitution are governed by only one state variable which is the consumption volatility, then the $\log$ consumption-wealth ratio has the form $x_{t}=\Phi_{0}+\Phi_{h} h_{t}$ and the logarithm of the SDF (5.8) becomes,

$$
m_{t, t+1}=p_{1}-p_{c} \Delta c_{t+1}-p_{h} \underbrace{\left(h_{t+1}-\frac{h_{t}}{\rho_{1}}\right)}_{\approx \Delta h_{t+1}},
$$

where $p_{1}=\theta \ln \delta-(1-\theta)\left(\rho_{0}+\left(1-\rho_{1}\right) \rho_{1}^{-1} \Phi_{0}\right)$ is a constant with no special interest at this stage $^{9}$. The discount coefficient $\rho_{1}$ has many asset pricing interpretations, among which those found in Campbell and Shiller (1988), Campbell $(1993,1996)$ and Campbell and Vuolteenaho (2004). The latter papers highlight the link of the coefficient $\rho_{1}$ to the average consumptionwealth ratio generated by a portfolio strategy of a mutual-fund investor who saves a fraction of his mutual fund every period to finance its consumption.

Since $\rho_{1} \approx 1$ as the frequency becomes high, the term $\left(h_{t+1}-\rho_{1}^{-1} h_{t}\right)$ will behave as $\Delta h_{t+1}$ and the logarithm of the SDF will be linear in consumption growth and changes in consumption volatility, where $p_{c}=\gamma$ is the standard price of level risk measured by the risk aversion parameter, and $p_{h}=-(1-\theta) \Phi_{h}$ is the price of volatility risk. The loading of the consumption-wealth ratio on consumption volatility and the price of volatility risk are given by:

$$
\begin{aligned}
\Phi_{h} & =-\frac{\rho_{1}}{2\left(1-\rho_{1} \phi_{h}\right)}(1-\gamma)\left(1-\frac{1}{\psi}\right) \\
p_{h} & =\frac{\rho_{1}}{2\left(1-\rho_{1} \phi_{h}\right)}(1-\gamma)\left(\gamma-\frac{1}{\psi}\right) .
\end{aligned}
$$

In the asset pricing literature, authors would agree that $\gamma>1$, whereas there is still no consensus on $\psi>1$ and $\psi^{-1}<\gamma$. Then, the sign of the parameter $\theta$ and its position with respect to one are still crucial for asset pricing results. Bansal, Khatchatrian and Yaron (2004) argue that a rise in economic uncertainty leads to a fall in asset prices. In particular the total investor's wealth will fall due to an increase in consumption volatility. To capture a positive

\footnotetext{
${ }^{9}$ The constant $\Phi_{0}$ is given by:

$$
\Phi_{0}=-\frac{\rho_{1}}{1-\rho_{1}}\left[\rho_{0}+\ln \delta+\left(1-\frac{1}{\psi}\right) \mu_{c}-\left(1-\phi_{h}\right) \mu_{h} \Phi_{h}+\frac{1}{2} \theta \sigma_{h}^{2} \Phi_{h}^{2}\right] .
$$
}


relation between consumption volatility and consumption-wealth ratio, the coefficient $\Phi_{h}$ that drives this effect should be positive. On the other hand, only the condition $\psi^{-1}<\gamma$ is required for the volatility risk price to be negative and this can still be the case if $\psi \leq 1$. When the EIS is equal to one, $\Phi_{h}$ is equal to zero and the consumption-wealth ratio is constant. In this case, the Campbell and Shiller's approximation is exact with $\rho_{1}=\delta$ and $x_{t}=\ln (1-\delta) .{ }^{10}$

The single horizon Euler condition (5.3) implies the multiple horizon Euler condition:

$$
E\left[M_{t, t+S} R_{i t, k, S} \mid \mathcal{J}_{t}\right]=1
$$

where $M_{t, t+S}=\prod_{j=1}^{S} M_{t+j-1, t+j}$ is the multiperiod SDF and $R_{i t, k, S}$ a compound long-horizon return defined in (2.1). The subscript of $M_{t, t+S}$ indicates that it is pricing $S$-period holding returns from time $t$ to time $t+S$. One can already observe that the logarithm of $M_{t, t+S}$ features the two important economic risk factors defined in Section 2:

$$
m_{t, t+S}=\log M_{t, t+S} \approx S p_{1}-p_{c} \Delta c_{t, S}-p_{h} \Delta h_{t, S}
$$

Equation (5.11) is also equivalent to:

$$
E\left[R_{i t, k, S}^{e}\right]=\operatorname{Cov}\left(-\frac{M_{t, t+S}}{E\left[M_{t, t+S}\right]}, R_{i t, k, S}^{e}\right) .
$$

From the equation (5.13), we can then derive the horizon-dependent relationship between risk premium and covariances between returns and factors. It suffices to replace the SDF $M_{t, t+S}$ by one of its log-linear approximations $\widetilde{M}_{t, t+S}$ where:

$$
\frac{\widetilde{M}_{t, t+S}}{E\left[M_{t, t+S}\right]}=1+\beta_{S}\left(m_{t, t+S}-E\left[m_{t, t+S}\right]\right) .
$$

The approximated SDF has the same mean as the true SDF and the coefficient $\beta_{S}$ would be positive to ensure a positive relationship between the SDF and its approximation. The special case $\beta_{S}=1$ is similar to the SDF approximation of Yogo (2005). Two other special cases are given by:

$$
\begin{aligned}
& \beta_{S}=\frac{1}{E\left[M_{t, t+S}\right]} \sqrt{\frac{\operatorname{Var}\left[M_{t, t+S}\right]}{\operatorname{Var}\left[m_{t, t+S}\right]}} \text { if } \operatorname{Var}\left[\widetilde{M}_{t, t+S}\right]=\operatorname{Var}\left[M_{t, t+S}\right] \\
& \beta_{S}=\frac{1}{E\left[M_{t, t+S}\right]} \frac{\operatorname{Cov}\left(M_{t, t+S}, m_{t, t+S}\right)}{\operatorname{Var}\left[m_{t, t+S}\right]} \text { if } \sqrt{E\left[\left(M_{t, t+S}-\widetilde{M}_{t, t+S}\right)^{2}\right]} \text { is minimum. }
\end{aligned}
$$

\footnotetext{
$$
\begin{aligned}
& q_{1}=-p_{1}+\mu_{c} p_{c}+\left(1-\phi_{h}\right) \mu_{h} p_{h}-\frac{1}{2} \sigma_{h}^{2} p_{h}^{2} \\
& q_{h}=\left(\frac{1}{\rho_{1}}-\phi_{h}\right) p_{h}+\frac{1}{2} p_{c}^{2} .
\end{aligned}
$$
}

${ }^{10}$ The logarithm of the risk-free rate implied by the model is given by $r_{f, t+1}=q_{1}-q_{h} h_{t}$ where: 
Substituting (5.14) in (5.13) yields:

$$
E\left[R_{i t, k, S}^{e}\right]=p_{c, S} \operatorname{Cov}\left(\xi_{\Delta c, t, S}, R_{i t, k, S}^{e}\right)+p_{h, S} \operatorname{Cov}\left(\xi_{\Delta h, t, S}, R_{i t, k, S}^{e}\right)
$$

where cross-sectional level and volatility risk prices are given by:

$$
p_{c, S}=\gamma \beta_{S} \text { and } p_{h, S}=p_{h} \beta_{S} .
$$

These prices are respectively positive and negative as observed, and constant across horizons if $\beta_{S}=1$. Given estimates and standard deviations of level and volatility risk prices shown in Table 6 at horizons $S>4$, the intersection of conventional confidence intervals for risk prices at these horizons is nonempty. This point is in favor of arguments which sustain that risk-price is constant across investment horizons, even if one unit risk is a different quantity from an horizon to the other.

More generally, choosing model parameters to match observed magnitudes of cross-sectional level and volatility risk prices will also depends on which approximation of the true SDF is used. It can be shown that the values of $\beta_{S}$ in special cases (5.15) and (5.16) are greater than one so that the magnitudes of cross-sectional level and volatility risk prices are respectively greater than the magnitudes of the risk aversion $\gamma$ and the loading $p_{h}$. From (5.10) it is straightforward that the magnitude of volatility risk price increases for a more risk-averse investor and/or a more persistent volatility process.

\subsection{Consumption Shares, Dividends, Price-Dividend Ratios and Returns}

Here we describe how we generate portfolio returns in the economy. Lettau and Wachter (2006) provide a model where benchmark assets are zero-coupon equities paying the aggregate dividend. Here we extend benchmark assets to zero-coupon securities paying dividends on long-lived assets. Let $P_{n, t}^{a}$ the price at date $t$ of the zero-coupon security paying $n$ periods later from $t$, the dividend on an arbitrary long-lived asset $a$. The arbitrary long-lived asset $a$ can be any long-lived primitive asset, any long-lived portfolio or the consumption claim. The Euler equation that requires the no-arbitrage condition for zero coupon securities is given by:

$$
P_{n, t}^{a}=E\left[M_{t, t+1} P_{n-1, t+1}^{a} \mid \mathcal{J}_{t}\right]
$$

with the trivial boundary condition $P_{0, t}^{a}=D_{t}^{a}$. Equation (5.19) can also be written:

$$
\frac{P_{n, t}^{a}}{D_{t}^{a}}=E\left[M_{t, t+1} \frac{S_{t+1}^{a}}{S_{t}^{a}} \frac{C_{t+1}}{C_{t}} \frac{P_{n-1, t+1}^{a}}{D_{t+1}^{a}} \mid \mathcal{J}_{t}\right],
$$


with the boundary condition:

$$
\frac{P_{0, t}^{a}}{D_{t}^{a}}=1
$$

and where $S_{t}^{a}$ denotes the dividend share of total consumption of the asset $a$ up to a multiplicative constant. Equation (5.20) is the same for all long-lived assets, and its solution depends on the dynamics of the dividend shares. Log dividend shares are usually modelled as stationary processes (see for example Menzly, Santos and Veronesi (2004)). This assumption has two main critical implications in discrete time setting. First, all asset dividends are cointegrated with consumption, with the same normalized cointegration vector $(1,-1)$. Second and more importantly, the stationarity of dividend shares implies that all dividends grow at the same rate as consumption. We assume instead that dividends are cointegrated with consumption and an asset specific random walk variable driven by consumption volatility, and that the cointegration vector is also specific to the asset. Furthermore, we assume that the right hand side of cointegration equations are linear combinations of a deterministic trend and a common stationary and persistent variable that helps capturing the predictable part of dividend growth. Formally, we write:

$$
\begin{aligned}
d_{t}^{a}-\left(1+\lambda_{c}^{a}\right) c_{t}-v_{t}^{a} & =\lambda_{0}^{a} t+\lambda_{z}^{a} z_{t} \\
z_{t+1} & =\phi_{z} z_{t}+\sigma_{z} \sqrt{h_{t}} \varepsilon_{t+1} \\
v_{t+1}^{a} & =v_{t}^{a}+\lambda_{h}^{a}\left(h_{t}-\mu_{h}\right)+\sigma_{v}^{a} \sqrt{h_{t}} u_{t+1}^{a},
\end{aligned}
$$

where $\left(\epsilon_{t+1}, \eta_{t+1}, \varepsilon_{t+1}, u_{t+1}^{a}\right)^{\top} \sim \mathcal{N}\left(0,\left(\begin{array}{cccc}1 & 0 & \rho & 0 \\ 0 & 1 & 0 & 0 \\ \rho & 0 & 1 & 0 \\ 0 & 0 & 0 & 1\end{array}\right)\right)$ with $\rho>0$.

Even if the choice of such a process can be justified on various grounds, the first reason why we depart from the common specification of stationary dividend share is an empirical one. Consumption growth and portfolio dividend growth series are very different in terms of mean as well as variance and other moments. Cointegration tests often reject the hypothesis of a cointegration between dividends and consumption (Hansen, Heaton and Li (2005)). However, if the cointegration is strongly assumed, it seems therefore empirically sound to choose a model that does not impose the same cointegration vector between consumption and all dividends as the majority of models do. The pattern of the log shares of the 25 Fama and French size and book-to-market sorted portfolios plotted in Figure 1 show the evidence of a trend either in variables or the cointegration equation. Table 2 confirms that mean dividend growths are 
very different across these portfolios. ${ }^{11}$

The imply dynamics of the asset dividend growth is given by:

$$
\begin{aligned}
\Delta d_{t}^{a}=\lambda_{0}^{a} & +\left(1+\lambda_{c}^{a}\right) \mu_{c}-\lambda_{z}^{a}\left(1-\phi_{z}\right) z_{t}+\lambda_{h}^{a}\left(h_{t}-\mu_{h}\right) \\
& +\sqrt{h_{t}}\left[\left(1+\lambda_{c}^{a}\right) \epsilon_{t+1}+\lambda_{z}^{a} \sigma_{z} \varepsilon_{t+1}+\sigma_{v}^{a} u_{t+1}^{a}\right] .
\end{aligned}
$$

Our model can then generate predictable dividend growths with different means, thanks to the cointegration coefficients of dividend and consumption. Moreover, if $\lambda_{0}^{a}=0, \lambda_{c}^{a}=0, \lambda_{h}^{a}=0$ and $\sigma_{v}^{a}=0$, then the dividend share is identified by $z_{t}$ up to an additive and a multiplicative constant. In this case, equation (5.24) implies that the dividend share captures the predictable component of the dividend growth. This last point is consistent with the view expressed in Lettau and Ludvigson (2005) that, if consumption follows a random walk like (5.6) and if the consumption-dividend ratio is stationary, then the consumption-dividend ratio captures the predictable component of the dividend growth. ${ }^{12}$ On the other hand,

$$
\text { if } \rho=1 \text { then } z_{t}=\sigma_{z} \sum_{j=0}^{\infty} \phi_{z}^{j}\left(\Delta c_{t-j}-\mu_{c}\right) \text {. }
$$

Then, in this particular case of our setting, the process $z_{t}$ almost plays a similar role as expected consumption growth in the Bansal and Yaron (2004)'s model in predicting the dividend growth using a variable that depends on past consumption levels. The coefficients $\lambda_{z}$ and $\lambda_{h}$ are negative so that dividends will increase following an increase in expected consumption growth and/or a fall in macroeconomic uncertainty.

Lettau and Wachter (2006) advocate the fact that if primitive assets are long-lived, then it is not easy to model their dividend shares stochastically in a discrete time setting, in a way similar to the continuous time setting of Menzly, Santos and Veronesi (2004), because of the difficulty to keep the shares between zero and one as well as their sum to one. However, equation (5.20) shows that we don't need to model the dividend share itself in order to compute the price-dividend ratio of a long-lived asset or portfolio. It is just sufficient to model the share up to a multiplicative constant. This constant is of no particular interest unless we need to completely characterize asset prices and not only asset valuation ratios (such as price-dividend ratios in our case). The fact is that when the shares are known up to a multiplicative constant, dividends and prices are also known up to the same multiplicative constant and that does not

\footnotetext{
${ }^{11}$ Equation (5.21) denotes the cointegration equation of asset $a$ up to an additive constant and specifies that the dividend share of the asset is stationary if and only if $\lambda_{0}^{a}=0, \lambda_{c}^{a}=0, \lambda_{h}^{a}=0$ and $\sigma_{h}^{a}=0$.

${ }^{12}$ In general, a model that aims at explaining only the aggregate market behavior will not require additional ingredients as for the complete cross-section of asset returns.
} 
affect the price-dividend ratio since the constant simplifies. For this reason, we drop the constant term in the cointegration equation (5.21) such that $s_{t}^{a}$ measures the share up to this constant in our study. ${ }^{13}$

For solving for zero-coupon security valuation ratios in this model, one conjectures that:

$$
\frac{P_{n, t}^{a}}{D_{t}^{a}}=\exp \left(A^{a}(n)+A_{z}^{a}(n) z_{t}+A_{h}^{a}(n) h_{t}\right) .
$$

The solution (5.27) for zero-coupon security valuation ratios then hold with:

$$
\begin{aligned}
A^{a}(n)= & p_{1}+\mu_{c}\left(1+\lambda_{c}^{a}-p_{c}\right)+\lambda_{0}^{a}-\lambda_{h}^{a} \mu_{h}+\left(1-\phi_{h}\right) \mu_{h}\left[A_{h}^{a}(n-1)-p_{h}\right] \\
& +\frac{1}{2} \sigma_{h}^{2}\left[A_{h}^{a}(n-1)-p_{h}\right]^{2}+A^{a}(n-1) \\
A_{z}^{a}(n)= & -\lambda_{z}^{a}\left(1-\phi_{z}\right)+\phi_{z} A_{z}^{a}(n-1) \\
A_{h}^{a}(n)= & \lambda_{h}^{a}+\frac{1}{2}\left(\sigma_{v}^{a}\right)^{2}+\frac{1}{2}\left(1+\lambda_{c}^{a}-p_{c}\right)^{2}+\rho\left(1+\lambda_{c}^{a}-p_{c}\right) \sigma_{z}\left[\lambda_{z}^{a}+A_{z}^{a}(n-1)\right] \\
& +\frac{1}{2} \sigma_{z}^{2}\left[\lambda_{z}^{a}+A_{z}^{a}(n-1)\right]^{2}+\left(\frac{1}{\rho_{1}}-\phi_{h}\right) p_{h}+\phi_{h} A_{h}^{a}(n-1),
\end{aligned}
$$

where $A^{a}(0)=0, A_{z}^{a}(0)=0$ and $A_{h}^{a}(0)=0$. The $A(\cdot)$ functions of all long-lived assets have the same recursion and differ only through the asset's specific parameter values $\lambda_{0}^{a}, \lambda_{c}^{a}, \lambda_{z}^{a}, \lambda_{h}^{a}$ and $\sigma_{v}^{a}$. The parameters $\lambda_{c}^{a}$ and $\lambda_{z}^{a}$ are constrained by the equation:

$$
\left(1+\lambda_{c}^{a}\right)+\rho \sigma_{z} \lambda_{z}^{a}=\chi^{a, c}
$$

where $\chi^{a, c}$ is the ratio of the covariance between consumption growth and the dividend growth of the asset $a$ to the mean of consumption volatility. This ensures that, increasing $\lambda_{z}^{a}$ will rise the asset premium by reducing the price-dividend ratio, so that value stocks will be assets with high magnitude of $\lambda_{z}^{a}$.

The price $P_{t}^{a}$ of the asset $a$ at date $t$ is the sum of prices of zero coupon securities paying future dividends on asset $a$. Then, the asset price-dividend ratio is given by the formula:

$$
\frac{P_{t}^{a}}{D_{t}^{a}}=\sum_{n=1}^{\infty} \exp \left(A^{a}(n)+A_{z}^{a}(n) z_{t}+A_{h}^{a}(n) h_{t}\right),
$$

where the $A(\cdot)$ functions are defined in (5.28), (5.29) and (5.30). The formula (5.31) is a nice way to compute the price-dividend ratio without a further analytical approximation of the

\footnotetext{
${ }^{13}$ Formally, if $\mathcal{A}$ is the set of all primitive long-lived assets, then there are positive constants $\beta^{a}$ such that:

$$
\sum_{a \in \mathcal{A}} \beta^{a} S_{t}^{a}<1
$$

The complement to one of the sum in (5.26) can then account for the shares of short-lived primitive assets as well as the share of labor income.
} 
asset return to asset $a$, similar to the approximation (5.5) of the return on the claim to the aggregate consumption. ${ }^{14}$ The gross return on asset $a$ is then given by:

$$
R_{t+1}^{a}=\frac{P_{t+1}^{a}+D_{t+1}^{a}}{P_{t}^{a}}=\left(\frac{P_{t+1}^{a}}{D_{t+1}^{a}}+1\right)\left(\frac{P_{t}^{a}}{D_{t}^{a}}\right)^{-1}\left(\frac{D_{t+1}^{a}}{D_{t}^{a}}\right),
$$

where the price-dividend ratio is given by (5.31) and the dividend growth by (5.24).

To understand how consumption volatility risks affect the more complex long-lived asset $a$, we follow Lettau and Wachter (2006) by concentrating on how these risks influence simple zero-coupon securities paying future dividends on the asset $a$. Let $R_{n, t+1}^{a}$ denote the one-period return on the zero-coupon security with the price $P_{n t}^{a}$ at the date $t$, that is:

$$
R_{n, t+1}^{a}=\frac{P_{n-1, t+1}^{a}}{P_{n t}^{a}}=\frac{P_{n-1, t+1}^{a}}{D_{t+1}^{a}}\left(\frac{P_{n t}^{a}}{D_{t}^{a}}\right)^{-1} \frac{D_{t+1}^{a}}{D_{t}^{a}} .
$$

Consumption level and consumption volatility risks of this zero-coupon security at one horizon are given by:

$$
\begin{aligned}
\operatorname{Cov}\left(r_{n, t+1}^{a}-r_{f, t+1}, \Delta c_{t+1}\right) & =\left[\chi^{a, c}+\rho \sigma_{z} A_{z}^{a}(n-1)\right] \mu_{h} \\
\operatorname{Cov}\left(r_{n, t+1}^{a}-r_{f, t+1}, \Delta h_{t+1}\right) & =\left[A_{h}^{a}(n-1)+A_{h}^{a}(n)-\lambda_{h}^{a}-q_{h}\right] \frac{\sigma_{h}^{2}}{1+\phi_{h}} .
\end{aligned}
$$

These equations also defined the term structure of one-horizon consumption level and consumption volatility risks of zero-coupon securities. Increasing the magnitude of $\lambda_{h}^{a}$ rises the volatility risk. Increasing the magnitude of $\lambda_{z}^{a}$ will increase both consumption level and consumption volatility risks. Assets with high magnitude of $\lambda_{z}^{a}$ will then have high risk premia. These assets with high risk premia will also be value stocks since increasing the magnitude of $\lambda_{z}^{a}$ also lowers the price-dividend ratio. This is consistent with an empirical result from Bansal, Dittmar and Lundblad (2005) that the coefficient of the projection of the dividend growth into an empirical proxy of expected consumption growth explains differences in risk compensation across assets. Since we find that consumption volatility is economically relevant as well for the cross-section, the innovation here is that to take macroeconomic uncertainty into account, the dividend growth can be projected into both an empirical proxy of expected consumption growth and that of consumption volatility. In addition to the coefficient $\lambda_{z}^{a}$, the resulting coefficient $\lambda_{h}^{a}$ then gives the possibility to explain cross-sectional differences in asset returns with further information about consumption which is provided by consumption volatility.

\footnotetext{
${ }^{14}$ The coefficients of the Campbell and Shiller (1988)'s approximation depend on preference parameters and empirical studies do not usually address this point. Garcia, Meddahi and Tedongap (2006) show how this approximation can affect some asset pricing statistics and their framework provide closed-form formulas of the Campbell and Shiller's coefficients.
} 


\subsection{Model Calibration and Implications for Stock Returns}

In this section, we follow previous studies by choosing reasonable parameter values which calibrate the model such that it reproduces important features of asset markets. We want the model to produce as possible portfolios whose return cross-section mimic that of the observed portfolios. However, since the model does not account for the size dimension, we concentrate on large portfolios to illustrate the empirical findings and choose parameters to match usual statistics. ${ }^{15}$ We calibrate the model at the quarterly frequency. Our value of the mean of the consumption growth corresponds to its sample counterpart $\mu_{c}=0.00555$. To calibrate the consumption volatility $h$, we convert the monthly volatility of Bansal and Yaron (2004) into a quarterly volatility, and use the corresponding parameter values. ${ }^{16}$ The resulting parameters for the consumption volatility are $\phi_{h}=0.962, \sigma_{h}=1.18 \times 10^{-5}$ and $\mu_{h}=1.83 \times 10^{-4}$. We use $\rho=1$ so that the process $z$ is a weighted combination of past consumption growth levels. Since in the Bansal and Yaron (2004)'s model demeaned expected consumption growth captures the predictable component of dividend growth, we convert it into a quarterly process and use the corresponding parameter values to calibrate the process $z$ that then plays a similar role in our model as we argue earlier. The procedure is similar to what we follow for the consumption volatility. The resulting parameters are $\phi_{z}=0.938$ and $\sigma_{z}=0.129$.

Our values of preference parameters are $\gamma=20$ for the risk aversion and $\psi=1$ for the EIS. These values are also used by Hansen, Heaton and Li (2005). We use $\delta=0.997$ and this quarterly value of the subjective discount factor corresponds to a monthly value of 0.999 also considered in previous studies. The parameters of the volatility process are higher than those estimated in the data. Higher values of the mean and the standard deviation of consumption volatility are necessary to generate actual risk premia as stated in Eraker (2006). The preference parameters consider in this study were not able to generate an annual equity premium larger than $1 \%$ using volatility parameters estimated in the data. Table 7 displays the complete parameter values used for the calibration assessment and the model implied statistics. The reported statistics are based on 1,000 Monte Carlo experiments, each with 252

\footnotetext{
${ }^{15}$ The model can account for the book-to-market dimension since it does for the dividend-to-price dimension which is similar. As this type of model performs well in explaining the aggregate stock market behavior (Bansal and Yaron (2004), Eraker (2006)), it will also perform well in the class of large portfolios which is the most closest to the market portfolio.

${ }^{16}$ To do so, we first represent monthly consumption volatility with a two-state Markov chain as in Garcia, Meddahi and Tedongap (2006). Then, we convert the monthly chain into a quarterly one by multiplying conditional mean and variance by three and compounding three times the transition probability matrix. Finally, we determine the coefficients of the $\mathrm{AR}(1)$ process represented by the quarterly Markov chain.
} 
Table 7: Simulation: Parameter Values and Model Implied Statistics for Large Book-to-Market Sorted Portfolios.

This table presents portfolio parameters as well as the annualized statistics of asset returns from simulated samples. Mean and standard deviation of excess returns, dividend growths and dividendprice ratios are in percentage.

\begin{tabular}{rrrrrrrrrrrr}
\multicolumn{1}{c}{ Parameters } \\
\hline Asset & $\lambda_{0}^{a}$ & $\lambda_{c}^{a}$ & $\lambda_{z}^{a}$ & $\lambda_{h}^{a}$ & $\sigma_{v}^{a}$ & $E\left[R^{e}\right]$ & $\sigma\left[R^{e}\right]$ & $E[\Delta d]$ & $\sigma[\Delta d]$ & $E\left[\frac{D}{P}\right]$ & $\sigma\left[\frac{D}{P}\right]$ \\
$(1)$ & $(2)$ & $(3)$ & $(4)$ & $(5)$ & $(6)$ & $(7)$ & $(8)$ & $(9)$ & $(10)$ & $(11)$ & $(12)$ \\
\hline S5B1 & -0.006 & 1.16 & -16 & -330 & 4.16 & 4.93 & 22.72 & 2.53 & 12.39 & 1.81 & 0.54 \\
S5B2 & -0.013 & 2.16 & -24 & -370 & 4.21 & 6.16 & 24.50 & 1.92 & 12.88 & 3.26 & 1.06 \\
S5B3 & -0.015 & 2.22 & -25 & -460 & 2.38 & 6.69 & 26.70 & 1.35 & 9.73 & 3.82 & 1.49 \\
S5B4 & -0.018 & 2.69 & -28 & -475 & 3.52 & 7.17 & 28.16 & 0.88 & 12.19 & 4.38 & 1.74 \\
S5B5 & -0.023 & 3.34 & -32 & -485 & 6.06 & 8.07 & 31.84 & 0.51 & 18.19 & 4.60 & 1.84 \\
& & & & & & & & & & & \\
\hline RF & & & & & 2.00 & 0.29 & & & & & \\
CONS & & & & & & & & & & & \\
\hline
\end{tabular}

quarterly observations. Increasing the size of the Monte Carlo makes little difference in the results.

We start with the analysis on implications for zero-coupon securities. Zero-coupon securities guaranteeing dividends on different assets have the same behavior but with different intensity since this intensity depends on the specific parameters of any asset. We illustrate the implications in the case of zero-coupon securities paying future dividends on the large value portfolio. Figure 13 displays the pattern of the $A(\cdot)$ functions characterizing the pricedividend ratio of a zero-coupon security. The function $A_{z}^{a}(n)$ is positive and increasing, and converges to $-\lambda_{z}^{a}$. The intuition behind this behavior is that higher levels of $z_{t}$ correspond to higher expected dividend growth, hence the price of the security that pays the asset dividend in the future will also be higher. The function $A_{h}^{a}(n)$ is negative so that a rise in macroeconomic uncertainty induces a fall in asset prices, and decreasing as well as the function $A^{a}(n)$ so that zero-coupon security prices diminish when the maturity increases. The decreasing and the convergence to $-\infty$ of the function $A^{a}(n)$ also constitutes a necessary condition for the convergence of the price-dividend ratio (5.31). Since zero-coupon securities with higher maturities have low prices, they are similar to value stocks and should be more riskier.

The term structure of consumption level and consumption volatility risks plotted in Fig- 
ure 14 confirms that risks are higher for longer maturities. Volatility risks are negative and decreasing so that long-maturity securities have higher negative covariances with variations in consumption volatility, as well as higher positive covariances with variations in consumption level than short-maturity securities. The model can then explain the differences in volatility risk premia across short-lived low-price securities and high-price securities in the maturity dimension.

We now examine the ability of the model to explain differences in volatility risk premia across long-lived low price-to-dividend stocks and high price-to-dividend stocks. We illustrate the implications in the set of large book-to-market sorted portfolios. While the overall fit of the statistics of these portfolios is reasonable as shown in Table 7, the model produces returns that are more volatile than in the data. This arise because the larger is the magnitude of the parameter $\lambda_{h}^{a}$, the larger is the return and its volatility. It is possible to simplify the model by setting the parameter $\lambda_{h}^{a}$ to zero for all assets. This will lower returns and their volatility and either a more higher parameter of risk aversion or elasticity of intertemporal substitution, or a more higher magnitude of the parameter $\lambda_{z}^{a}$ will be necessary for the model to generate actual returns. In consequence, it will produce low price-dividend ratios than in the data. ${ }^{17}$

Figure 15 shows the pattern of volatility risks computed via simulation across large bookto-market sorted portfolios and for one-period holding returns. Figure 16 shows the same pattern for full-period returns. $S$-volatility risks for one-period and full-period holding stocks respectively are negative with a downward trend as the horizon increases, a pattern observed in Figures 9 and 11 which plots the similar measure of volatility risk in the data. On the other hand, $S$-volatility risk for full-period portfolios computed from the model is negative and displays a similar pattern as the same measure computed from the data. The most important point shown in Figure 16 is the gap between volatility risks for the extreme value and the extreme growth portfolios. The large value is more riskier as in the data. The slightly difference between the data and the model occurs for the semi-growth and the semi-value portfolios. Their volatility risks are more closer to that of the extreme value portfolio than in the data. However, as in the data, there is just a little gap between these risks. The more pronounced trend of all these patterns in the model are explained with the fact that consumption volatility is more persistent in the model than in the data. However, the overall message is clear and states that the model replicates the findings in the data that consumption

\footnotetext{
${ }^{17}$ The results of Bansal and Yaron (2004) also suggest that increase the magnitude of the risk aversion lowers the price-dividend ratio and rises the equity premium. With a risk aversion parameter of 7.5 in their model, they report a price-dividend ratio of 25.02 and an equity premium of 4.01 for the aggregate stock. With a risk aversion parameter of 10 , the reported values are respectively 19.98 and 6.84 .
} 
volatility risks account for the differences in risk premia across portfolios sorted from growth to value.

\section{Conclusion}

Investors have concerns about consumption volatility because they fear the repercussion of macroeconomic uncertainty on their future wealth. We establish empirical facts supporting that short-period returns are mostly correlated to short-horizon variation in consumption volatility, and that there is a stable long-run relationship between returns and consumption volatility. The estimation of long-run consumption volatility risk price in the cross-section of long-period returns provides a significant estimate with a negative sign. We have also shown that this uncertainty on macroeconomic growth has the potential to explain differences in risk premia across the 25 Fama and French size and book-to-market sorted portfolios, even in the presence of long-run consumption risk. We finally show that a reduced form consumptionbased general equilibrium model similar to those considered in previous studies for explaining the aggregate stock market behavior can also rationalize the empirical findings. 


\section{References}

[1] Adrian, T., and J. Rosenberg (2006). Stock Returns and Volatility: Pricing the ShortRun and Long-Run Components of Market Risk. Federal Reserve Bank of New York Staff Report 254.

[2] Ahn, Seung C., and Christopher Gadarowski (1999). Small Sample Properties of the Model Specification Test Based on the Hansen-Jagannathan Distance. Manuscript, Dept. Econ., Arizona State Univ.

[3] Ang, A., R. J. Hodrick, Y. Xing, and X. Zhang (2006). The Cross-Section of Volatility and Expected Returns. Journal of Finance 61, 259-299.

[4] Bansal, R. (2005). Long Run Risks and Risk Compensation in Equity Markets. Handbook of Investments: Equity Risk Premium, edited by Rajnish Mehra.

[5] Bansal, R., R. F. Dittmar and D. Kiku (2005). Long Run Risks and Equity Returns. Duke University and National Bureau of Economic Research.

[6] Bansal, R., R. F. Dittmar and C. T. Lundblad (2005). Consumption, Dividends, and the Cross-Section of Equity Returns. Journal of Finance forthcoming.

[7] Bansal, R., V. Khatchatrian and A. Yaron (2004). Interpretable Asset Markets? Duke University and National Bureau of Economic Research.

[8] Bansal, R. and A. Yaron (2004). Risks for the Long Run: A Potential Resolution of Asset Pricing Puzzles. Journal of Finance 59, 1481-1509.

[9] Bonomo, M. and R. Garcia (1993). Disappointment Aversion as a Solution to the Equity Premium and the Risk-Free Rate Puzzles. CRDE Discussion Paper 2793, Université de Montréal.

[10] Brainard, William C., William R. Nelson, and Matthew D. Shapiro (1991). The Consumption Beta Explains Expected Returns at Long Horizons. Manuscript, Dept. Econ., Yale Univ.

[11] Breeden, Douglas T., Michael R. Gibbons, and Robert H. Litzenberger (1989). Empirical Tests of the Consumption-Oriented CAPM. Journal of Finance 44, 231-62.

[12] Campbell, J. Y. (1993). Intertemporal Asset Pricing without Consumption Data. American Economic Review 83, 487-512. 
[13] Campbell, John Y. (1996). Understanding Risk and Return. Journal of Political Economy 104, 298-345.

[14] Campbell, John Y. (1999). Asset Prices, Consumption, and the Business Cycle. In Handbook of Macroeconomics, vol. 1C, edited by John B. Taylor and Michael Woodford. Amsterdam: Elsevier Sci.

[15] Campbell, J. (2002). Consumption-Based Asset Pricing. Havard University and NBER.

[16] Campbell, J. Y. and T. Vuolteenaho (2003). Bad Beta, Good Beta. Harvard University.

[17] Cochrane, John H. (1996). A Cross-Sectional Test of an Investment-Based Asset Pricing Model. Journal of Political Economy 104, 572-621.

[18] Cochrane, John H. (2001). Asset Pricing. Princeton, NJ: Princeton Univ. Press.

[19] Cochrane, John H. (2006). Financial Markets and the Real Econony. Graduate School of Business. University of Chicago

[20] Epstein, L. G. and S. E. Zin (1989). Substitution, Risk Aversion and the Temporal Behavior of Consumption and Asset Returns: A Theoretical Framework. Econometrica 57, 937-969.

[21] Eraker, Bjørn. (2006). Affine General Equilibrium Models. Duke University. Working Paper.

[22] Fama, Eugene F., and Kenneth R. French (1992). The Cross-Section of Expected Stock Returns. Journal of Finance 47, 427-65.

[23] Fama, Eugene F., and Kenneth R. French (1993). Common Risk Factors in the Returns on Stocks and Bonds. Journal of Financial Economics 33, 3-56.

[24] Fama, Eugene F., and James D. MacBeth (1973). Risk, Return, and Equilibrium: Empirical Tests. Journal of Political Economy 81, 607-36.

[25] Ferson, Wayne E., and Stephen R. Foerster (1994). Finite Sample Properties of the Generalized Method of Moments in Tests of Conditional Asset Pricing Models. Journal of Financial Economics 36, 29-55.

[26] Garcia, R., N. Meddahi and R. Tedongap (2006). An Analytical Framework for Assessing Asset Pricing Model and Predictability. Université de Montréal. 
[27] Garcia, R., E. Renault and A. Semenov (2004). A Consumption CAPM with a Reference Level. CIRANO working paper series.

[28] Hansen, Lars Peter. (1982). Large Sample Properties of Generalized Method of Moments Estimators. Econometrica 50, 1029-54.

[29] Hansen, L.P., J. Heaton, and Nan Li (2005). Consumption Strikes Back? Measuring Long-Run Risks. University of Chicago.

[30] Hansen, Lars Peter, John Heaton, and Amir Yaron (1996). Finite-Sample Properties of Some Alternative GMM Estimators. Journal of Business and Economic Statistics. 14, $262-80$.

[31] Hansen, Lars Peter, and Ravi Jagannathan (1997). Assessing Specification Errors in Stochastic Discount Factor Models. Journal of Finance 52, 557-90.

[32] Hansen, Lars Peter, and Kenneth J. Singleton (1982). Generalized Instrumental Variables Estimation of Nonlinear Rational Expectations Models. Econometrica 50, 1269-86.

[33] Hayashi, Fumio. (2000). Econometrics. Princeton, NJ: Princeton Univ. Press.

[34] Jacobs, Kris and Kevin Q. Wang (2004). Idiosyncratic Consumption Risk and the CrossSection of Asset Returns. Journal of Finance LIX vol. 5, 2211-2252.

[35] Jagannathan, Ravi, and Zhenyu Wang (1996). The Conditional CAPM and the CrossSection of Expected Returns. Journal of Finance 51, 3-53.

[36] Jagannathan, Ravi, and Zhenyu Wang (1998). An Asymptotic Theory for Estimating Beta-Pricing Models Using Cross-Sectional Regression. Journal of Finance 53, 1285-1309.

[37] Kan, Raymond M., and Chu Zhang (1999). Two-Pass Tests of Asset Pricing Models with Useless Factors. Journal of Finance 54, 203-35.

[38] Kandel, Shmuel, and Robert F. Stambaugh (1990). Expectations and Volatility of Consumption and Asset Returns. Review of Financial Studies 3 (2), 207-32.

[39] Kandel, Shmuel and Robert F. Stambaugh (1995). Portfolio Inefficiency and the CrossSection of Expected returns. Journal of Finance 50, 157-184.

[40] Lettau, Martin, and Sydney C. Ludvigson (2005). Expected returns and expected dividend growth. Journal of Financial Economics 76, 583-626. 
[41] Lettau, Martin, and Sydney Ludvigson (2001a). Consumption, AggregateWealth, and Expected Stock Returns. Journal of Finance 56, 815-49.

[42] Lettau, Martin, and Sydney Ludvigson (2001b). Resurrecting the (C)CAPM: A CrossSectional Test When Risk Premia Are Time-Varying. Journal of Political Economy 109, $1238-87$.

[43] Lettau, M., S. C. Ludvigson and J. A. Wachter (2006). The Declining Equity Premium: What Role Does Macroeconomic Play? Review of Financial Studies, forthcoming.

[44] Lettau, M. and J. A. Wachter (2006). Why is long-horizon equity less risky? A durationbased explanation of the value premium. Journal of Finance, forthcoming.

[45] Mehra, Rajnish, and Edward C. Prescott (1985). The Equity Premium: A Puzzle. Journal of Monetary Economics 15, 145-61.

[46] Newey, Whitney K., and Kenneth D.West (1987). A Simple, Positive Semi-definite, Heteroskedasticity and Autocorrelation Consistent Covariance Matrix. Econometrica 55, $703-8$.

[47] Parker, J. A. and C. Julliard (2005). Consumption Risk and the Cross-Section of Expected Returns. Journal of Political Economy 113(1), 185-222.

[48] Roll, Richard and Stephen A. Ross (1994). On the Cross-sectional Relation Between Expected Returns and Betas. Journal of Finance 49, 101-121.

[49] Santos, Tano, and Pietro Veronesi (2004). Labor Income and Predictable Stock Returns. Review of Financial Studies, forthcoming.

[50] Tauchen, G. (2005). Stochastic Volatility in General Equilibrium. Duke University.

[51] Tedongap, Romeo (2005). External Habit in Recursive Utility. (Work in progress). Université de Montréal and CIREQ.

[52] Yogo, M. (2005). A Consumption-Based Explanation of Expected Stock Returns. Manuscript, Dept. Econ., Harvard University. 
Figure 1: Log Shares for Size and Book-to-Market Sorted Portfolios: 1963:2-2005:2. This figure presents the pattern of log shares for the 25 Fama and French size and book-to-market sorted portfolios.
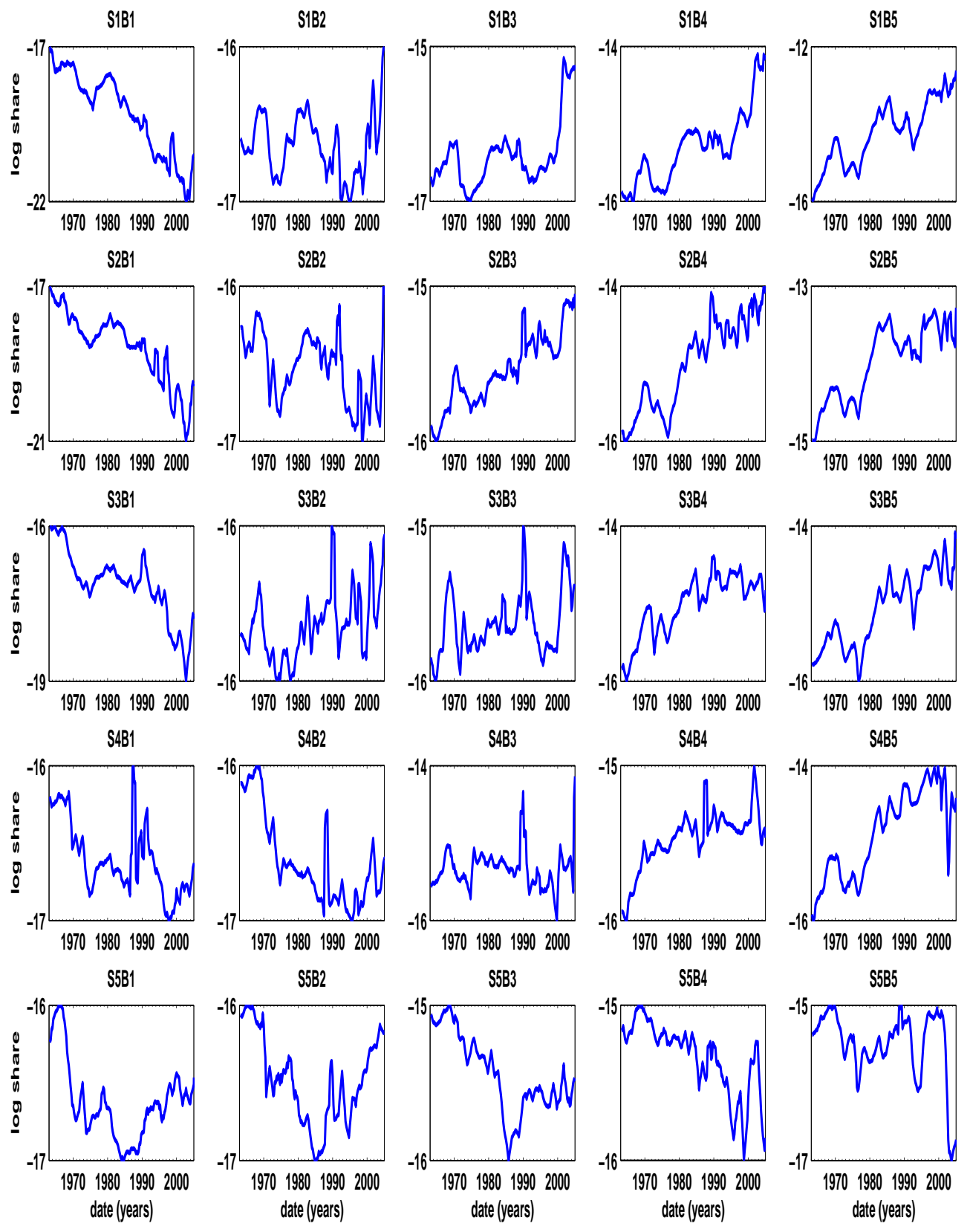
Figure 2: $S$-volatility Risk for One-Period Growth and Value Portfolios $(k=1)$.

This figure presents the pattern of $S$-volatility risk across growth and value portfolios. Risks are computed as covariances of returns with variations in consumption volatility.
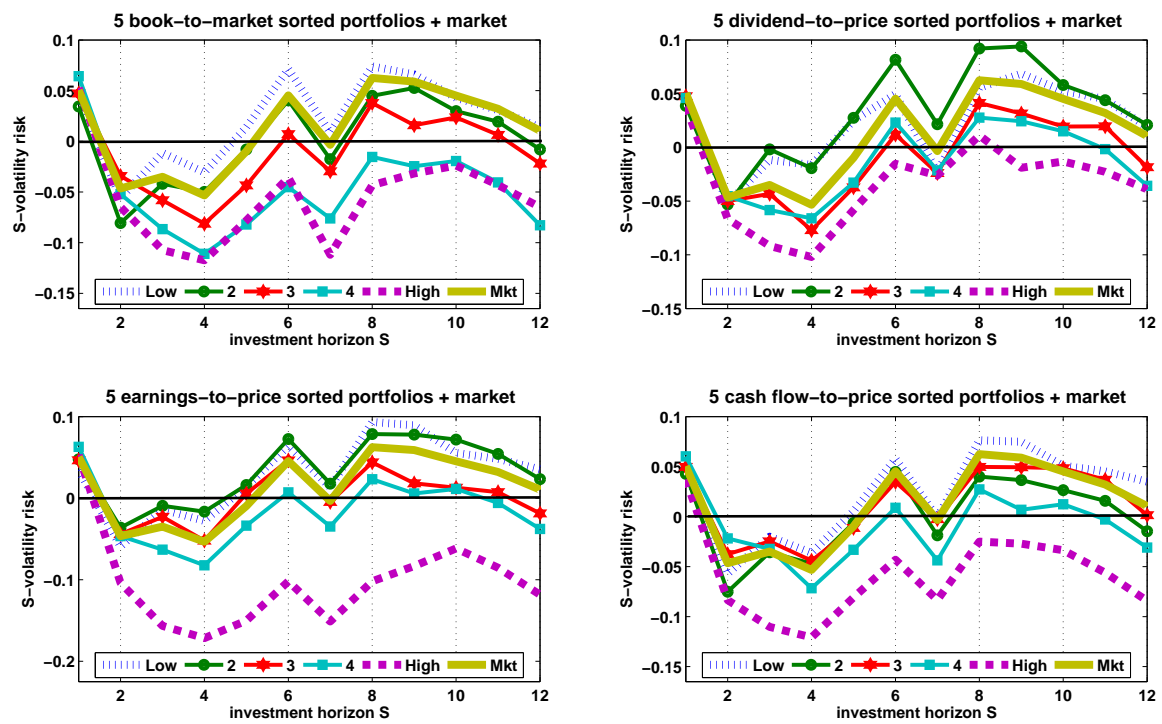

Figure 3: $S$-level Risk for One-Period Growth and Value Portfolios $(k=1)$.

This figure presents the pattern of $S$-level risk across growth and value portfolios. Risks are computed as covariances of returns with variations in consumption level.
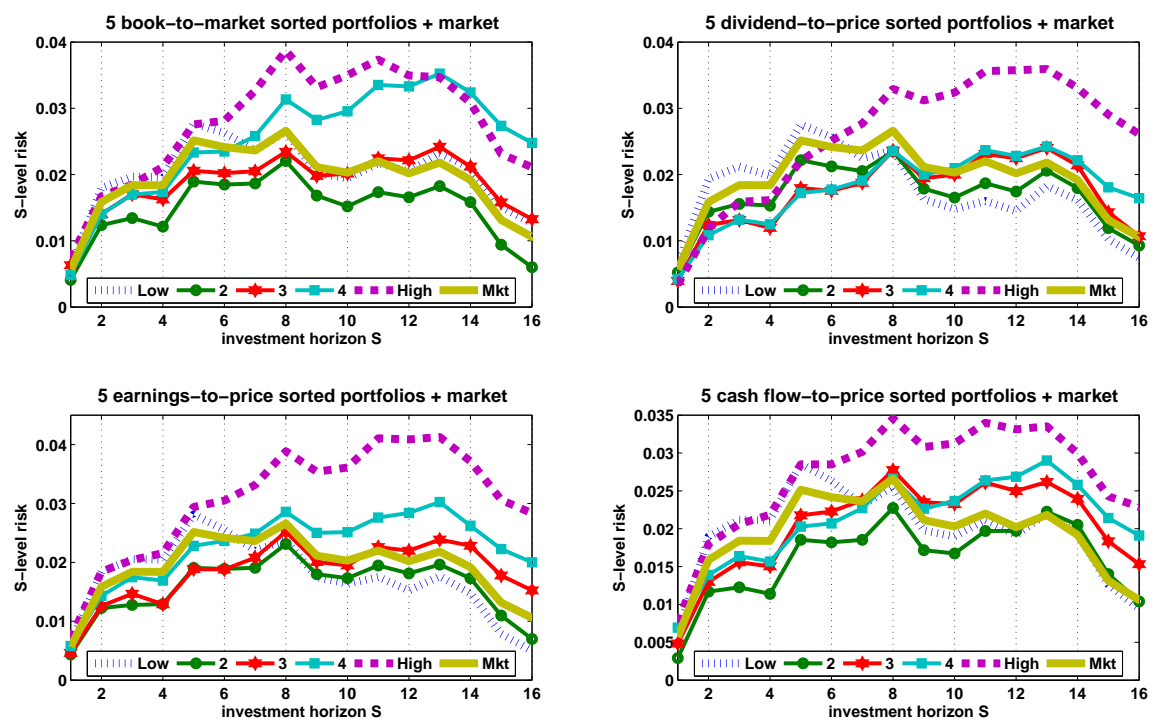
Figure 4: $S$-volatility Risk for Long-Horizon Growth and Value Portfolios $(k=S)$. This figure presents the pattern of $S$-volatility risk across long-horizon growth and value portfolios. Risks are computed as covariances of returns with variations in consumption volatility.
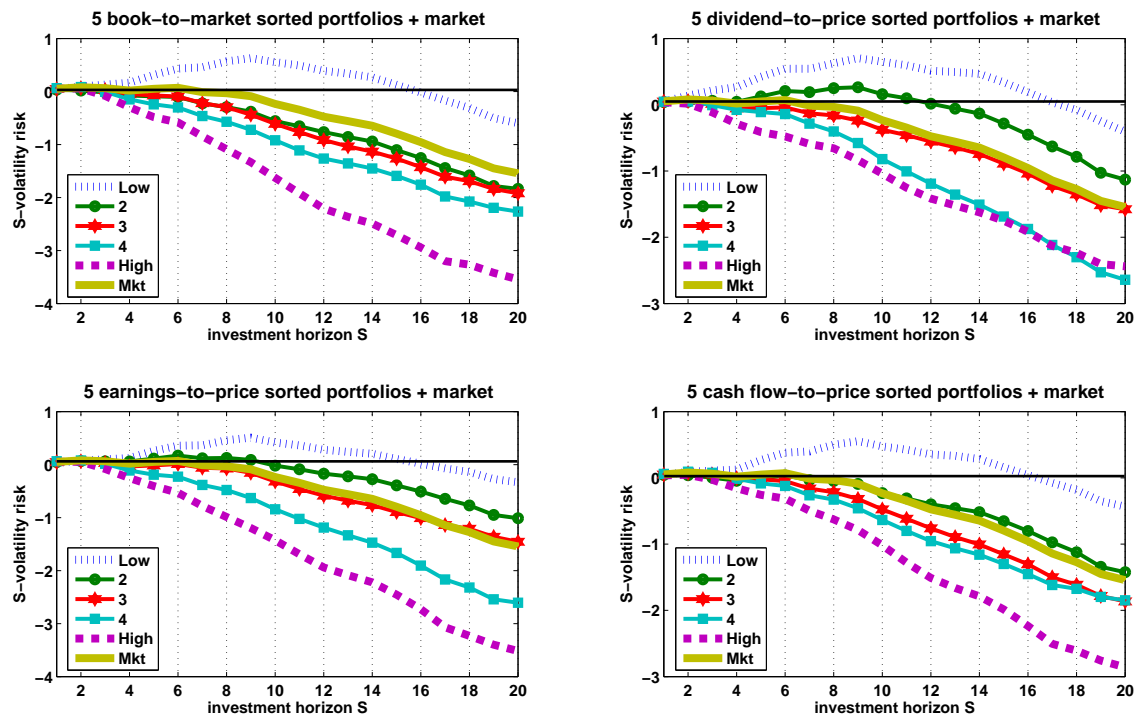

Figure 5: $S$-level Risk for Long-horizon Growth and Value Portfolios $(k=S)$.

This figure presents the pattern of $S$-level risk across long-horizon growth and value portfolios. Risks are computed as covariances of returns with variations in consumption level.
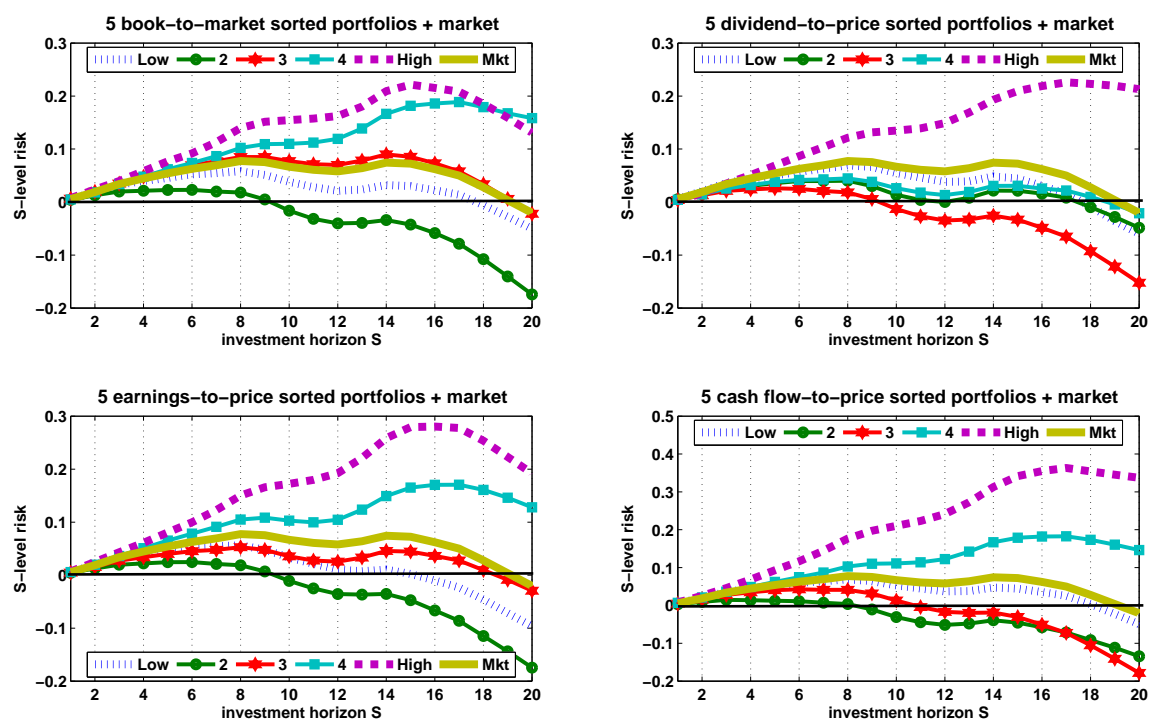
Figure 6: Cross-Sectional Correlations, by Investment Horizon, Between Risk Premium and Consumption Level and Consumption Volatility Risks.

This figure presents the patterns of $\rho_{r c}(S, k)$ and $\rho_{r h}(S, k)$ for $k=1$ and $k=S$, while $S$ varies from 1 to 20 .

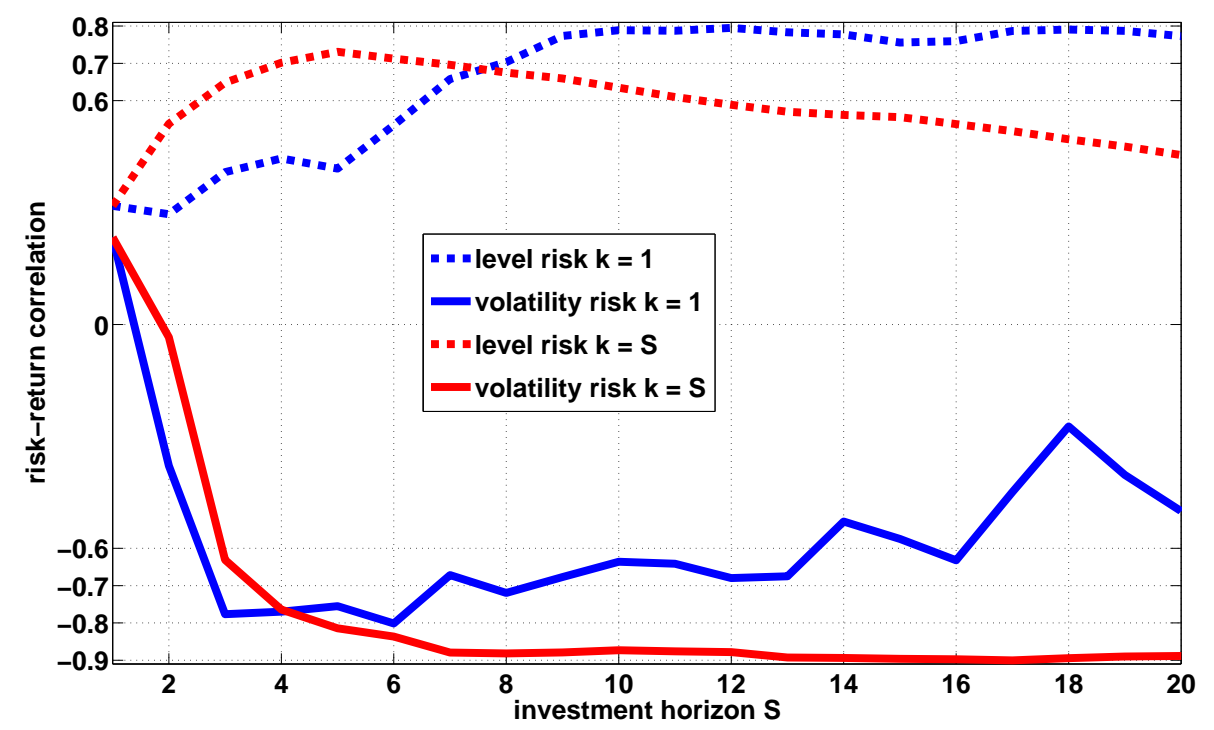


Figure 7: Cross-Sectional Correlations, by Investment Horizon, Between Risk Premium and Consumption Level and Consumption Volatility Risks.

This figure presents the patterns of $\rho_{r c}(S, k)$ and $\rho_{r h}(S, k)$ when $k$ is fixed to 4,8 and 12 , while $S$ varies from $k$ to 20 .

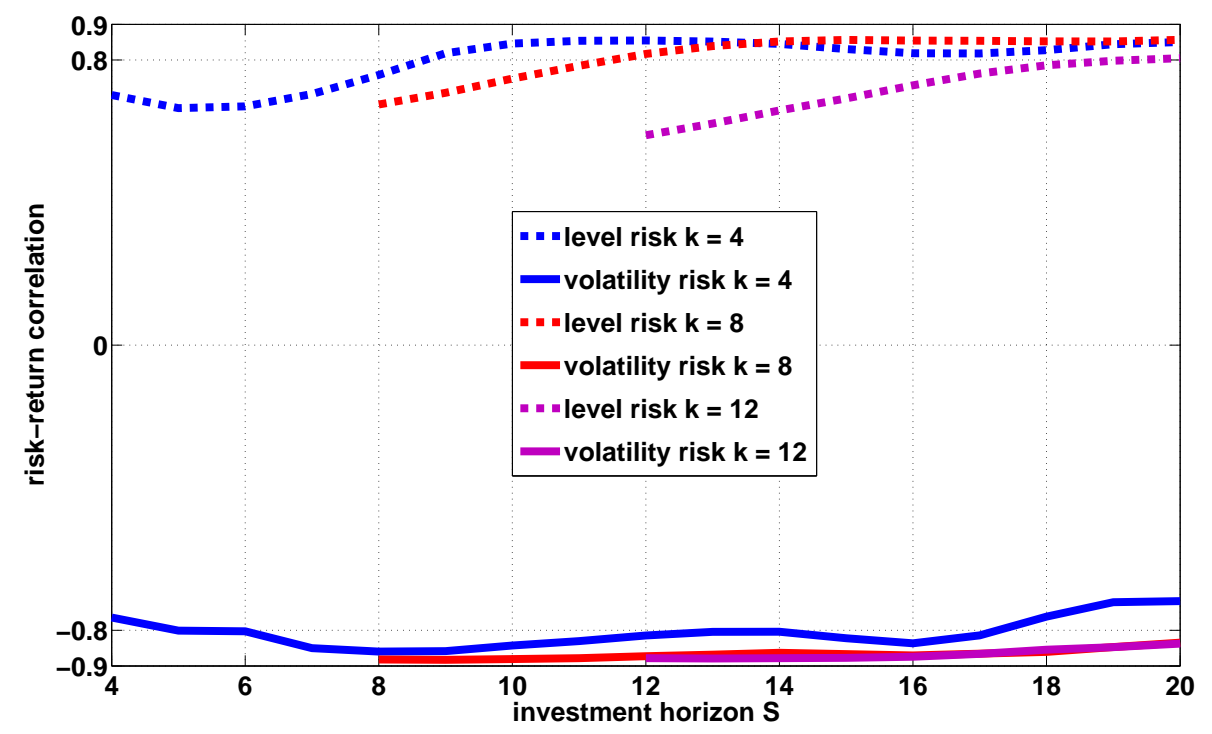


Figure 8: Cross-Sectional Correlations, by Stock Holding Period, Between Risk Premium and Consumption Level and Consumption Volatility Risks.

This figure presents the patterns of $\rho_{r c}(S, k)$ and $\rho_{r h}(S, k)$ when $S$ is fixed to 8, 12, 16 and 20, while $k$ varies from 1 to $S$.

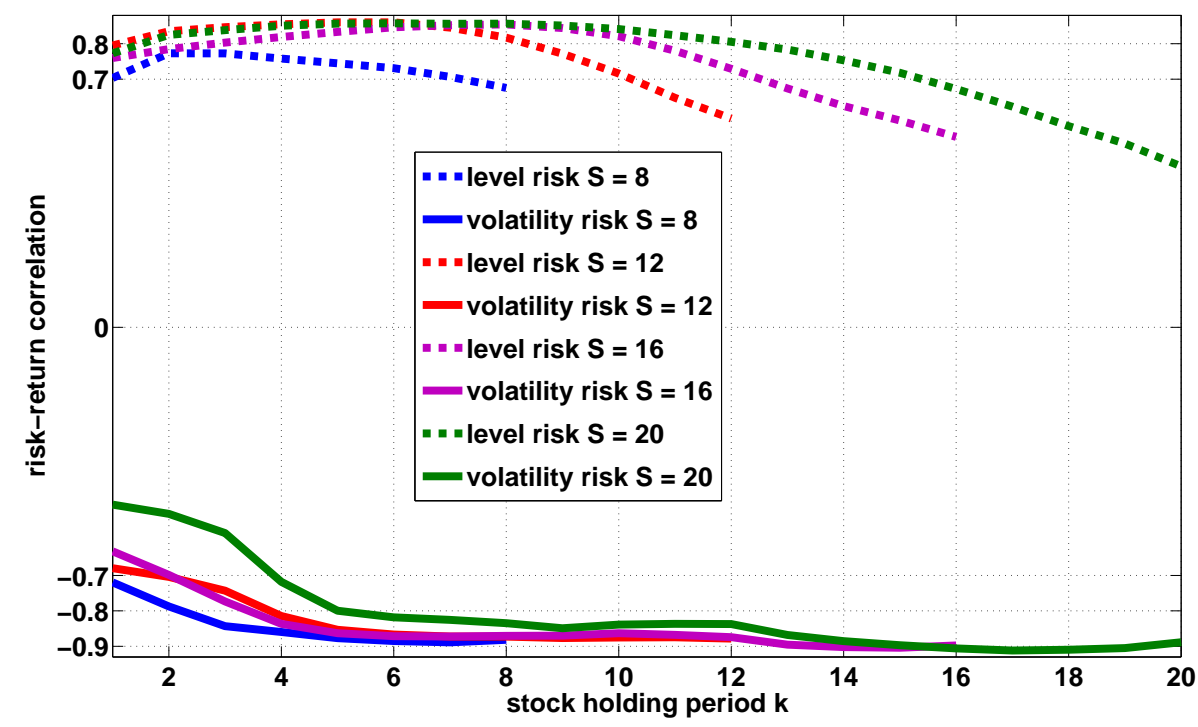


Figure 9: $S$-volatility risk for One-Period Book-to-Market Sorted Portfolios in Size Dimension $(k=1)$.

This figure presents the pattern of $S$-volatility risk across one-period book-to-market sorted portfolios in size dimension. Risks are computed as covariances of returns with variations in consumption volatility.
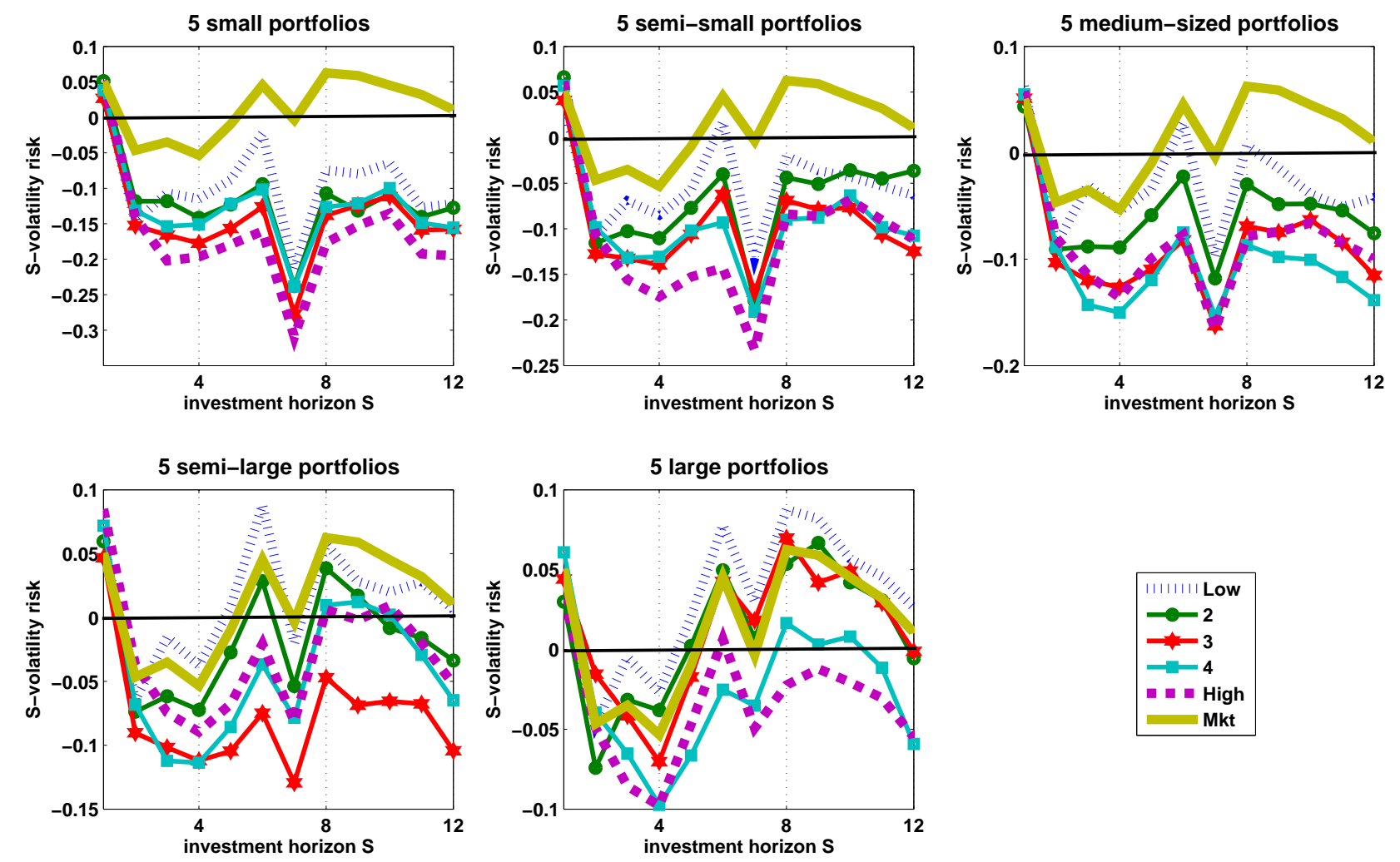
Figure 10: $S$-level risk for One-Period Book-to-Market Sorted Portfolios in Size Dimension $(k=1)$.

This figure presents the pattern of $S$-level risk across one-period book-to-market sorted portfolios in size dimension. Risks are computed as covariances of returns with variations in consumption level.
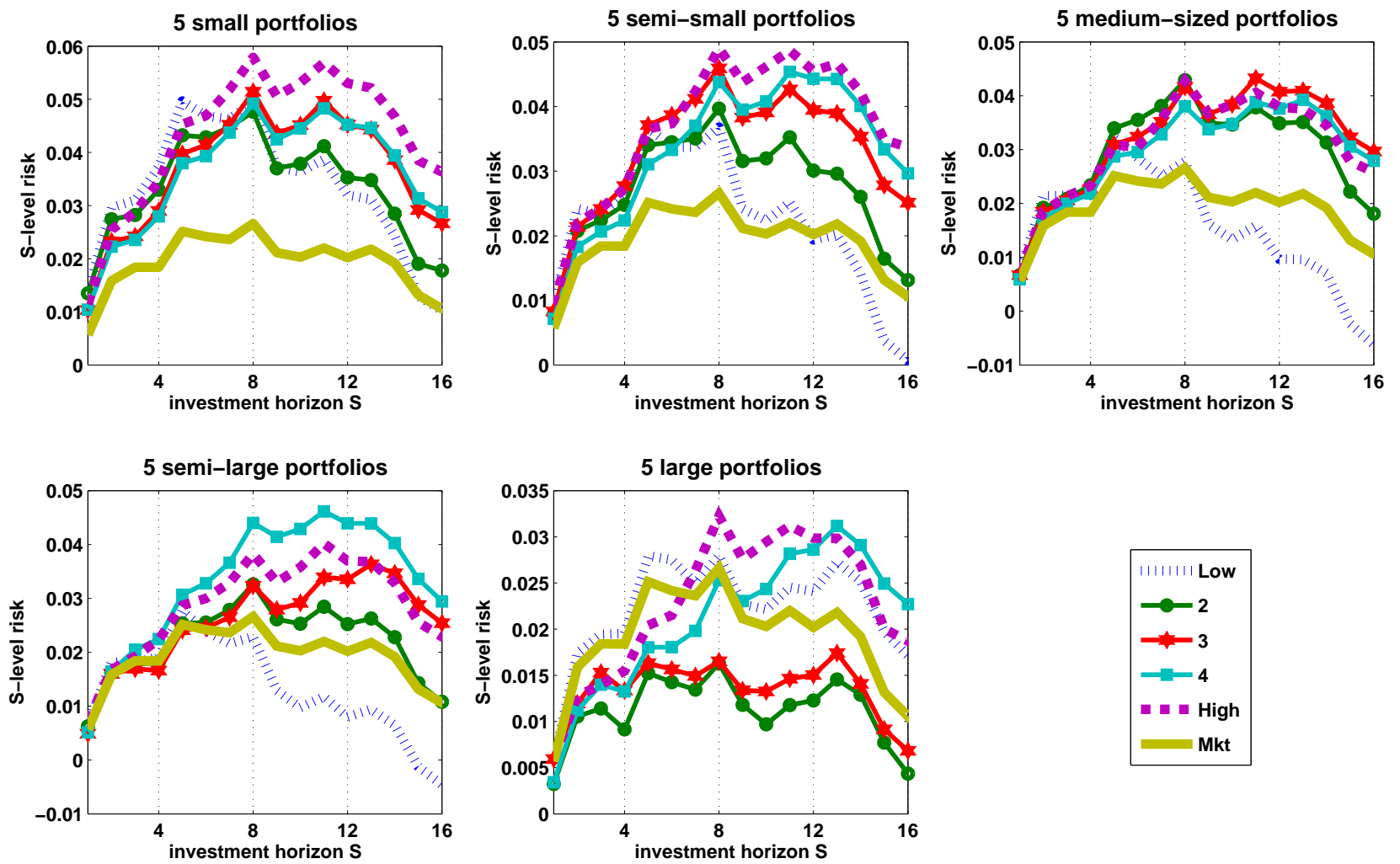
Figure 11: $S$-volatility risk for Long-Horizon Book-to-Market Sorted Portfolios in Size Dimension $(k=S)$.

This figure presents the pattern of $S$-volatility risk across long-horizon book-to-market sorted portfolios in size dimension. Risks are computed as covariances of returns with variations in consumption volatility.
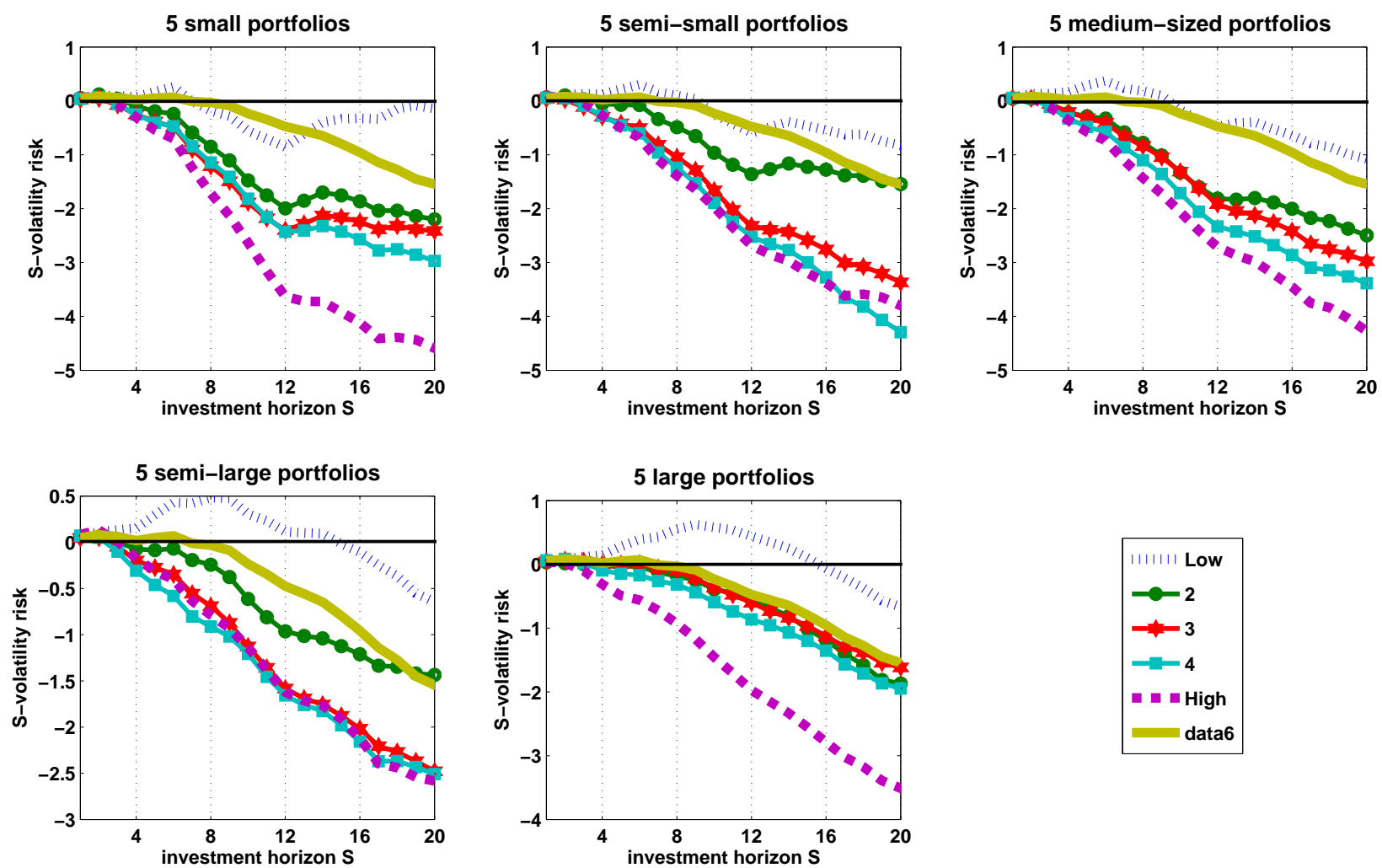
Figure 12: $S$-level risk for Long-Horizon Book-to-Market Sorted Portfolios in Size Dimension $(k=S)$.

This figure presents the pattern of $S$-level risk across long-horizon book-to-market sorted portfolios in size dimension. Risks are computed as covariances of returns with variations in consumption level.
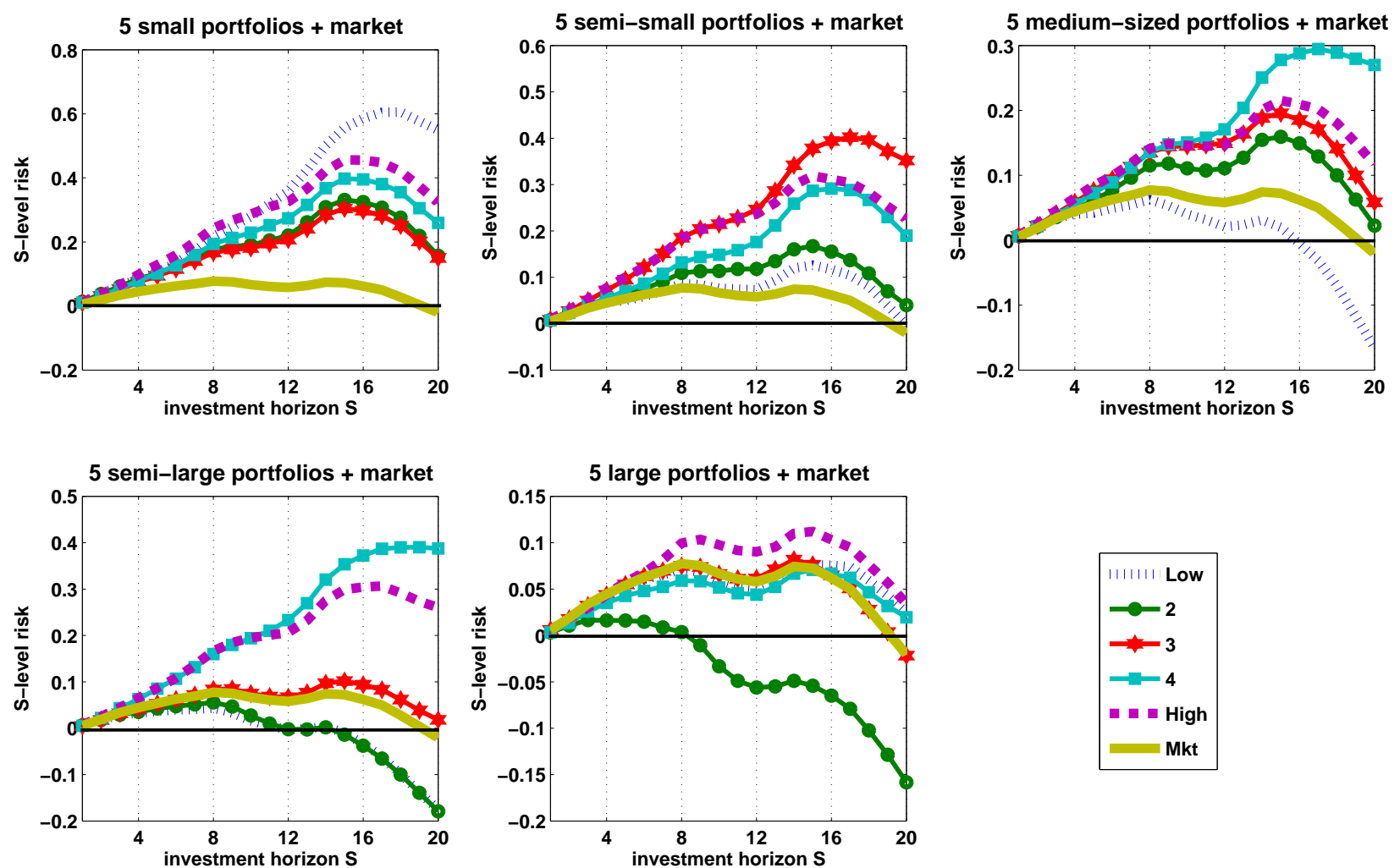

investment horizon $\mathrm{S}$ 


\section{Figure 13: Plot of the $A(\cdot)$ Functions}

This figure presents the pattern of the $A(\cdot)$ functions for the case of the large value portfolio.
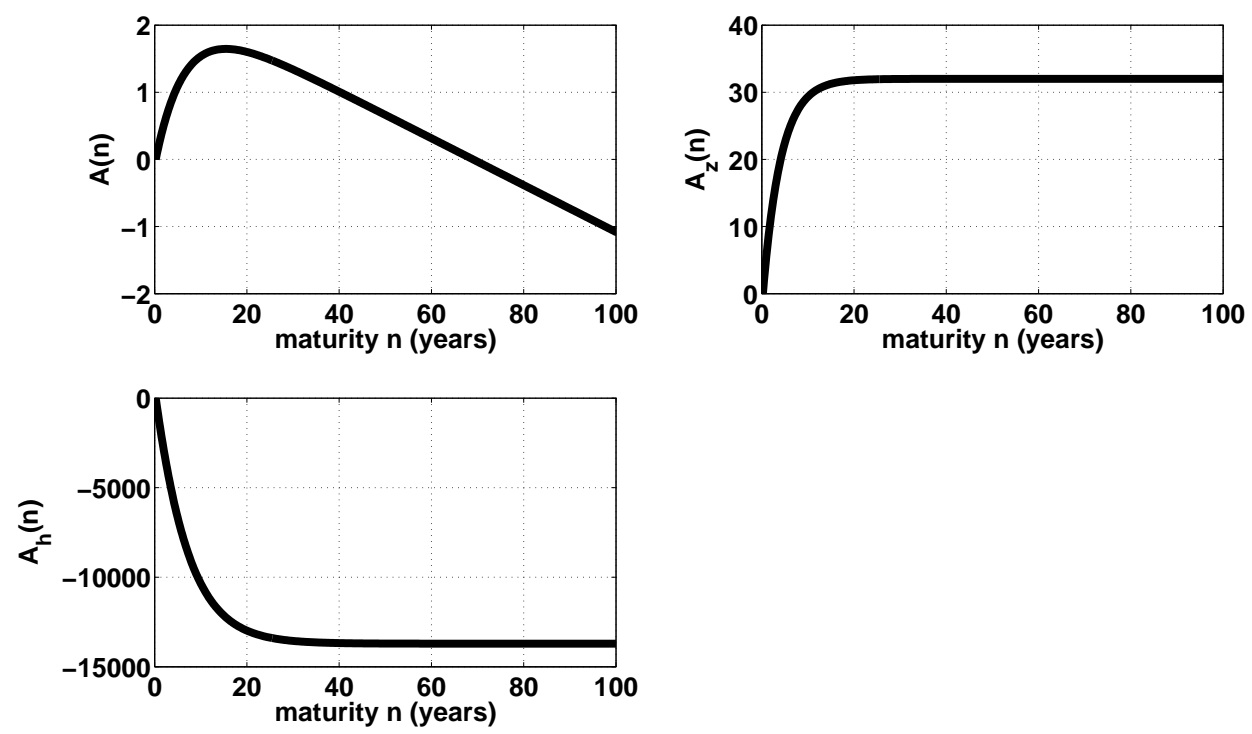

Figure 14: Term Structure of consumption level and consumption volatility risks.

This figure presents the term of consumption level and consumption volatility risks for zero-coupon security paying future dividends on the large value portfolio.
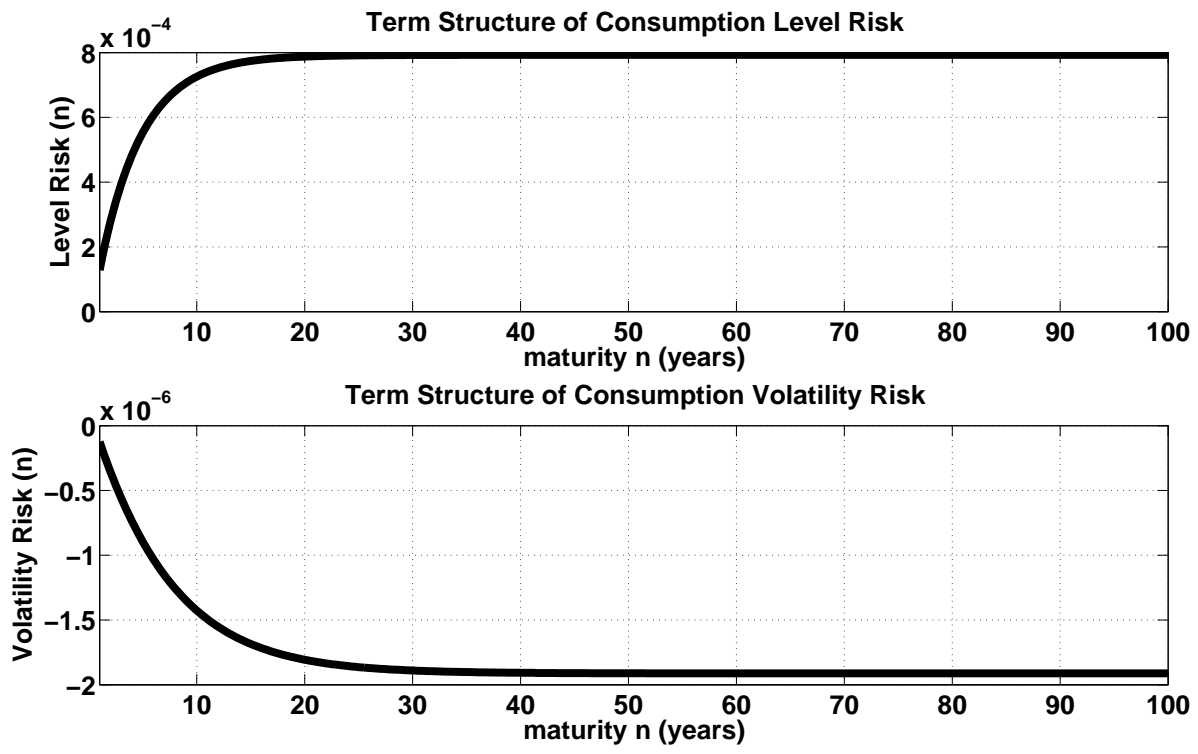
Figure 15: Simulation: Volatility Risk for Large Book-to-Market Sorted Portfolios $(k=1)$.

This figure presents the pattern of volatility risks across large book-to-market sorted portfolios.

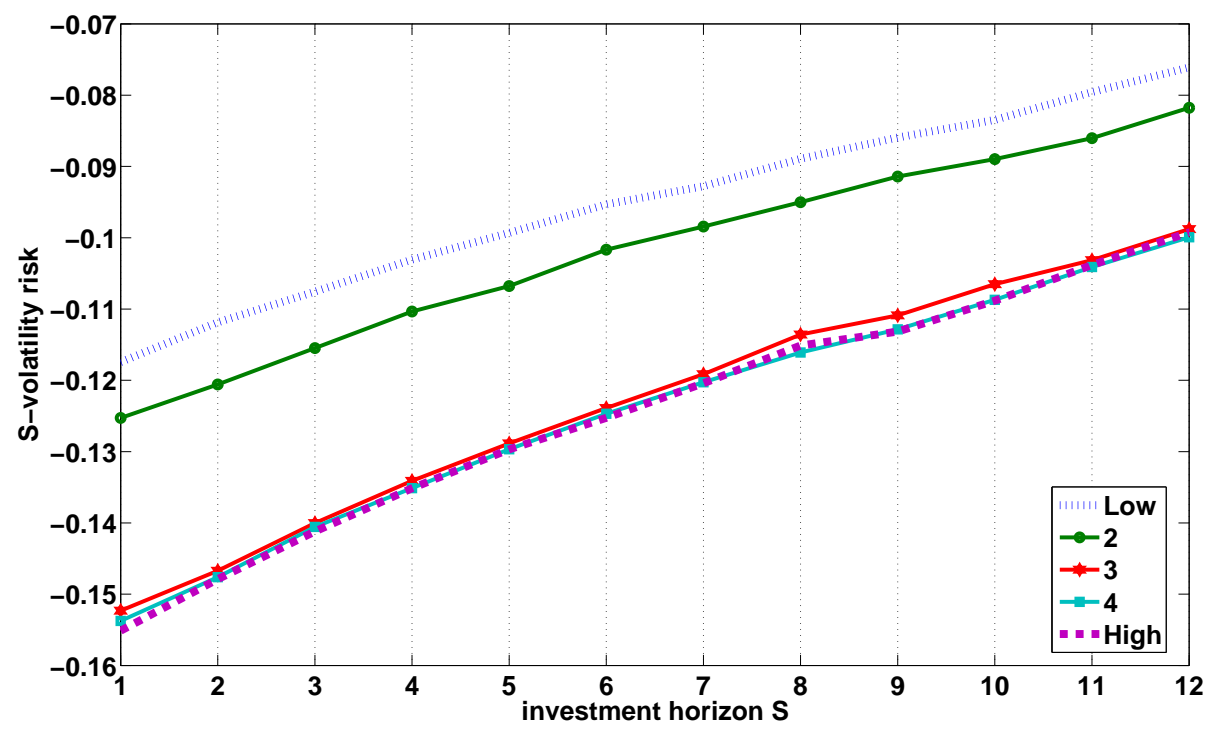

Figure 16: Simulation: Volatility Risk for Large Book-to-Market Sorted Portfolios $(k=S)$.

This figure presents the pattern of volatility risks across large book-to-market sorted portfolios.

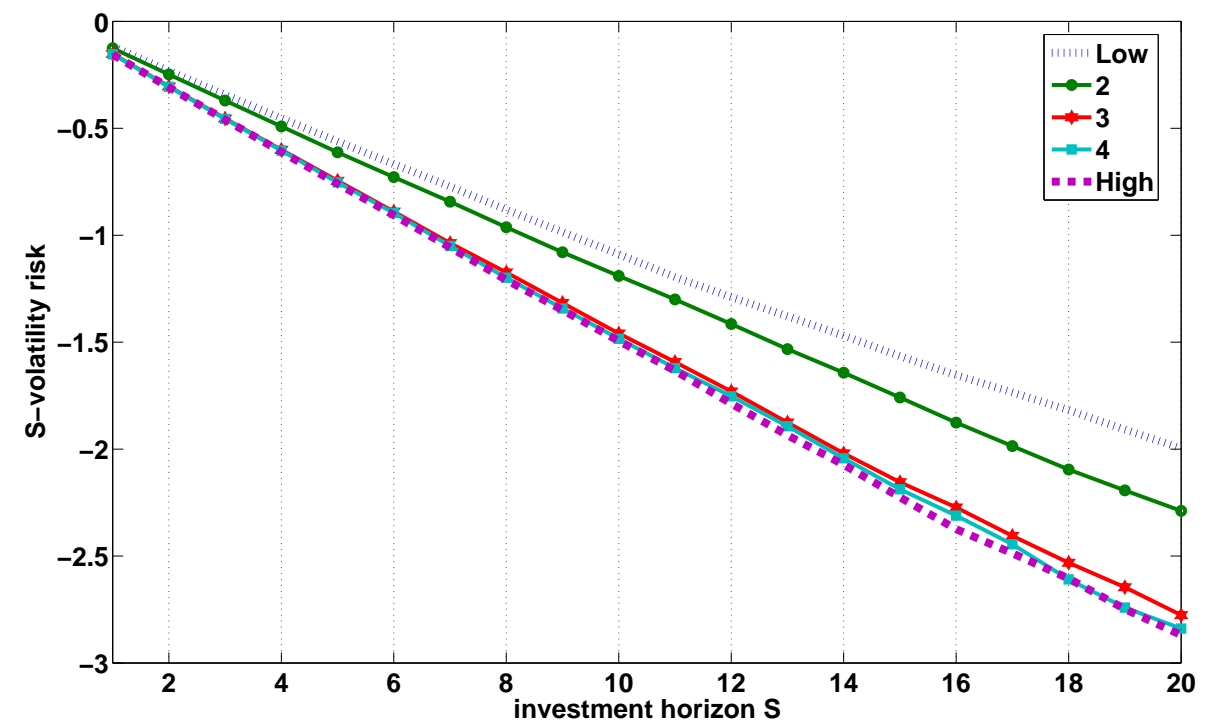

